NBER WORKING PAPER SERIES

\title{
MIGRATION, SPECIALIZATION, AND TRADE: EVIDENCE FROM BRAZIL'S MARCH TO THE WEST
}

\author{
Heitor S. Pellegrina \\ Sebastian Sotelo \\ Working Paper 28421 \\ http://www.nber.org/papers/w28421 \\ NATIONAL BUREAU OF ECONOMIC RESEARCH \\ 1050 Massachusetts Avenue \\ Cambridge, MA 02138 \\ January 2021
}

We thank Dominick Bartelme, Jonathan Eaton, Andrei Levchenko, Steve Redding, Esteban Rossi-Hansberg, and Matthew Turner for helpful comments, as well as Walter Steingress, João Paulo Pessoa, and Ferdinando Monte for useful discussions. We also thank participants in seminars at Purdue, Michigan, NYU Abu Dhabi, St. Louis Fed, IADB, TIGN-LACEA, Middlebury, RMET, UEA, FGV/EESP, Banco Central de Colombia, Insper, UFABC, Banco Central de Chile, UCLA, Berkeley ARE, Aarhus, the World Bank, NBER Agricultural Trade Policy, ETOS-FREIT, Princeton, CAF, SBE 2020 Meeting, and the Econometric Society 2021 Meetings. Andrés Fajardo, Natalia Martinez Camelo, Brian Cevallos Fujiy, and Elliot Kang provided excellent research assistance. Financial support from the Michigan Institute for Teaching and Research in Economics (MITRE) is gratefully acknowledged. Sotelo thanks the IES at Princeton for its hospitality and funding during part of this research. E-mail: heitor.pellegrina@nyu.edu and ssotelo@umich.edu. All errors are our own. The views expressed herein are those of the authors and do not necessarily reflect the views of the National Bureau of Economic Research.

NBER working papers are circulated for discussion and comment purposes. They have not been peer-reviewed or been subject to the review by the NBER Board of Directors that accompanies official NBER publications.

(C) 2021 by Heitor S. Pellegrina and Sebastian Sotelo. All rights reserved. Short sections of text, not to exceed two paragraphs, may be quoted without explicit permission provided that full credit, including $\odot$ notice, is given to the source. 
Migration, Specialization, and Trade: Evidence from Brazil's March to the West Heitor S. Pellegrina and Sebastian Sotelo

NBER Working Paper No. 28421

January 2021

JEL No. F10,F16,Q17,R23

\section{ABSTRACT}

Exploiting a large migration of farmers to the West of Brazil between 1950 and 2010, we study how migration shapes aggregate and regional comparative advantage. We document that farmers emigrating from regions with high employment in an activity are more likely to work in that activity and have higher income than other migrants doing so. We incorporate this heterogeneity into a quantitative model and find that, by reshaping comparative advantage, declines in migration costs contributed substantially to Brazil's rise as a leading commodity exporter. Opportunities to migrate, moreover, account for a substantial share of the gains from trade.

Heitor S. Pellegrina

A5 Office 1995

NYU Abu Dhabi, Saadiyat Campus

bu Dhabi, UAE

heitor.pellegrina@nyu.edu

Sebastian Sotelo

University of Michigan, Ann Arbor

Department of Economics

611 Tappan Ave

Ann Arbor, MI 49109

United States

ssotelo@umich.edu

A data appendix is available at http://www.nber.org/data-appendix/w28421 


\section{Introduction}

A central task in international trade, and in spatial economics more generally, is to understand the impact of trade on welfare and on the patterns of specialization across locations. Seeking to quantify the consequences of trade, a recent literature has incorporated comparative advantage - differences in relative costs across locations and activities - into quantitative models and established it as a major determinant of trade flows. ${ }^{1}$ But while recent work has also documented that comparative advantage itself evolves over time, there has been comparatively less progress in quantifying the mechanisms that drive that evolution.

The starting point of this paper is the observation that episodes of large internal migration are common, and that they are often associated with dramatic changes in the sectoral and spatial composition of economic activity of the countries experiencing them. Consider, for example, the U.S. westward expansion and, more recently, the large migration of Chinese workers to export-oriented clusters. Across the world, moreover, rural-urban migration is a hallmark of development.

Based on this observation, we ask: How does migration within a country shape regional and aggregate comparative advantage? We consider three channels. First, migration determines the allocation of labor across regions and activities that differ in their natural advantage. Second, migration alters the relative abundance of land and labor across regions. Third, workers whose knowledge is heterogeneous across activities sort according to their own comparative advantage, which determines the labor supply composition across economic activities and regions. To measure the strength of these mechanisms, we incorporate them into a quantitative spatial model, which we then take to data from Brazil in the second half of the 20th century.

We focus on an episode often called the "March to the West" (Villas Bôas and Villas Bôas, 1994 and Nehring, 2016). Starting in the 1950s and following a series of public initiatives to integrate the country's West to the urban centers in the East, a large number of Brazilian workers migrated to low-density, high productivity-growth areas in the Cerrado and the Amazon. As a result, the share of Brazil's population living in the West grew from 7 to 15 percent between 1950 and 2010, while that region's participation in total agricultural production and total land use also rose sharply. ${ }^{2}$

\footnotetext{
${ }^{1}$ Eaton and Kortum (2012) discuss the recent revival of Ricardian trade theory. Costinot and RodríguezClare (2015) review the welfare implications of a wide class of quantitative models, including those based on comparative advantage.

${ }^{2}$ This episode involved the migration of approximately 8 million workers from the East to the West of Brazil. This magnitude is comparable to that of other migration episodes in which government policy played a role. For example, the Transmigration Program in Indonesia (Bazzi, Gaduh, Rothenberg, and Wong, 2016) resettled 2 million migrants, and in China the stock of migrants across provinces increased by 15 million
} 
Our paper begins by documenting three empirical facts that guide our modeling approach, and to that end, we construct a data set that combines several waves of Brazil's demographic census with production and trade data since the 1950s. Over the course of the March, Brazil's agricultural sector was transformed: it developed a comparative advantage in new commodities, and it became a leading global exporter of those new commodities. Specifically, using an index of comparative advantage, we first show that Brazil's exports increasingly specialized in soy, beef, and corn (relative to the rest of the world). ${ }^{3}$ Likewise, these commodities' share in total exports grew from nearly zero to about 13 percent, while the share of commodities that had been traditional mainstays of Brazil's external sector, such as coffee, cacao, and bananas, declined sharply. Second, Eastern migrants comprise about 30 percent of the West's labor force in 2010, but this share varies greatly across agricultural activities and is particularly large for soy. Third, there is a strong link between a migrant's origin and her income and employment activity choice. We compare farmers who emigrate from different origin regions but end up in the same destination and working in the same activity. We find that farmers coming from a region with 1 percent larger employment in that activity earn 0.02 to 0.08 percent larger incomes and that their number is 0.07 to 0.16 percent larger than those of other regions.

Guided by these facts, we develop an overlapping generations model of trade with many activities and heterogeneous workers. Workers in our model are endowed with good-specific knowledge, which they acquire through exposure to economic activity in their origin region, and choose the location and activity that is best suited to that knowledge. In equilibrium, regional and aggregate comparative advantage reflect a combination of natural advantage, the abundance of labor, and the knowledge of the labor force.

Using a pared down version of our model, we obtain two analytical results. Our first result shows that the impact of migration costs on comparative advantage - defined as autarky opportunity costs - is ambiguous. By spreading knowledge across regions, migration undoes the ex-ante spatial allocation of worker knowledge, and doing so may amplify or reduce opportunity cost differentials relative to the rest of the world. In addition, migration modifies the link between comparative advantage and realized patterns of trade specialization. The reason is that, when opening up to trade, regions within a country compete both for domestic workers and for goods markets. A region's production costs, therefore, depend not only on its own productivity, but also on the productivity of all the other regions to which workers can migrate. Our second result introduces a statistic that reveals the mechanisms driving our between 2000 and 2005, enabled by changes in the houkou system (Tombe and Zhu, 2019).

${ }^{3}$ According to FAOSTAT, by 2010, Brazil was among the top three world exporters in soy, beef, and corn; as of 2018 it was the largest exporter of soy and beef. 
quantitative results. In our model, the non-migrant employment share in a region-activity pair is a sufficient statistic for the impact of migrants on comparative advantage (along the lines of Arkolakis, Costinot, and Rodriguez-Clare, 2012).

In bringing our model to the data, we identify key parameters that control worker heterogeneity and mobility, based on our reduced form elasticities relating migrants' activity and income to their regions of origin. We also calibrate the rest of the parameters to match production by region and activity between 1950 and 2010. We then conduct an experiment to gauge the consequences of migration cost reductions that induce labor reallocation. Specifically, we shut down the evolution of migration costs since the 1950s, while allowing all other exogenous factors to evolve over time, and we compare the evolution of this counterfactual economy to our baseline.

We find that the evolution of migration costs was critical in settling the West, accounting for half of the growth of that region's population share. Turning to trade, had migration costs not declined, trade specialization in agricultural goods in 2010 would have been pervasively lower across Western regions. In line with our theoretical results, the observed exposure of each region and activity to workers migrating from the East is strongly associated with these changes in specialization, because this exposure captures the direct impact of limiting migration on relative marginal costs. Aggregating these regional counterfactual changes yields large swings in specialization in new commodities for the West as a whole: specialization drops by 58 percent for soy and by 35 percent for beef and corn.

While migration is a key driver of the West's transformation, in Eastern regions, which were already densely populated in 1950, its impact is minor. Nonetheless, reductions in migration costs are critical to understand Brazil's country-wide international specialization in agriculture. Soy and beef specialization are 29 and 25 percent lower in 2010, absent migration cost reductions. The observed drop in migration costs, moreover, accounts for up to 30 percent of the observed evolution of Brazil's specialization between 1950 and 2010 (or 27 percent of the of the export share growth of these commodities).

We next assess how our margins of comparative advantage shape the impact of migration. Due to the essential role that heterogeneity in land productivity plays in agriculture, we keep this feature in our next two exercises. First, we measure the role of differences in land intensity across crops and land abundance across regions. Absent migration, regions in the West experience a negative labor-supply shock whose impact is smaller for land-intensive activities. In our baseline, this mechanism mitigates the impact of migration on agriculture, which is land intensive relative to manufacturing. Allowing for land-intensity heterogeneity within agriculture, the impact of migration on cattle ranching declines by about 5 percent in aggregate (17 percent for the West) because this is a particularly land-intensive activity; 
the response of the other activities is modest.

Second, we measure the contribution of heterogeneity in workers' knowledge. We recalibrate our model shutting down knowledge heterogeneity and find that this heterogeneity amplifies the impact of migration on aggregate trade, albeit with different magnitudes across crops. In the West, worker heterogeneity is quantitatively important to understand the disparate expansion of several agricultural activities, both new and traditional. In the aggregate, the role of worker heterogeneity is particularly strong for soybean - accounting for about one-ninth of our baseline results - , but for other crops, it is more muted. In addition, worker heterogeneity and migration strengthen the link between trade specialization and natural advantage in the long-run. Quantitatively, this channel operates most strongly again for soy, doubling its aggregate export and revenue shares, relative to a model without knowledge.

We close our investigation by studying welfare. We offer a decomposition that shows that the full gains from trade (i.e. welfare costs of not being able to trade with any other region) depend critically on the ability of workers to migrate. Migration opportunities, in fact, account for up to $60 \%$ of the gains from trade. In addition, regional comparative advantage has a large quantitative impact on how migration shapes the gains from trade. Finally, we show that East-West migration interacted with regional comparative advantage (relative to the rest of the world), often increasing the gains from international trade. ${ }^{4}$

Our paper relates to several strands of previous work. First, we contribute to a literature that measures the sources and evolution of comparative advantage in international trade. Levchenko and Zhang (2016) and Hanson, Lind, and Muendler (2015) document substantial changes in Ricardian comparative advantage over time and across countries. Morrow (2010) and Chor (2010) show that forces such as relative productivity and factor abundance differences are key drivers of comparative advantage. Other work has studied the role of alternative sources of comparative advantage, such as institutional differences (Levchenko, 2007, Nunn, 2007, and Manova, 2013), the unobservable dispersion of workers' abilities (Grossman and Maggi, 2000, Bombardini, Gallipoli, and Pupato, 2012, Ohnsorge and Trefler, 2007) and, related to our empirical findings, international migration (Bahar and Rapoport, 2016). ${ }^{5}$ We contribute to this literature in two ways. First, we establish conditions under which domestic migration determines the evolution of regional and national comparative advantage, through Ricardian and Heckscher-Ohlin forces and by reallocating activity-specific knowledge over

\footnotetext{
${ }^{4}$ We allow for endogenous expansions of the agricultural frontier, but we do not incorporate their welfare cost due to deforestation. Although it is an important issue, carefully measuring those costs is challenging, and we leave it for future research.

${ }^{5}$ Buera and Oberfield (2016) and Cai, Li, and Santacreu (2019), among others, study how the diffusion of ideas in an open economy shapes international comparative advantage (see Lind and Ramondo, 2018).
} 
space - a hitherto unexplored mechanism. Second, we show that in an economy in which heterogeneous regions compete for workers, regional comparative advantage does not fully determine realized trade specialization.

This paper also relates to a recent literature that measures the impact of agricultural trade on welfare (Costinot and Donaldson, 2014, Allen and Atkin, 2016, Porteous, 2019, Pellegrina, 2020, Sotelo, 2020), development and structural change (Tombe, 2015, Farrokhi and Pellegrina, 2020, Porteous, 2020), and the welfare implications of climate change (Costinot, Donaldson, and Smith, 2016, Gouel and Laborde, 2018). In most of this literature, comparative advantage is static and arises from differences in exogenous factors, such as the quality of land, factor proportions, or both. We show that taking advantage of those exogenous factors requires availability of workers and their knowledge. Our paper also clarifies our understanding of Brazil's emergence as a major global player in commodity markets, a unique episode that transformed international agricultural markets. ${ }^{6}$

Our quantitative analysis deploys the tools of the spatial economics literature studying the interaction of goods and people mobility, including Allen and Arkolakis (2014), Cosar and Fajgelbaum (2016), Redding (2016), Bryan and Morten (2019), Tombe and Zhu (2019), Morten and Oliveira (2016), Porcher (2020), and Fujiwara, Morales, and Porcher (2020) (see Redding and Rossi-Hansberg, 2017 for a recent review). Fajgelbaum and Redding (2014), in particular, explore how the domestic allocation of workers interacted with international comparative advantage to contribute to structural change and urbanization in 19th century Argentina. Different from that paper, we focus here on the role of migration costs and worker heterogeneity. ${ }^{7}$ Building on the recent dynamic approaches of Allen and Donaldson (2020) and Caliendo, Dvorkin, and Parro (2019), we also add to this literature a new source of complementarity between trade and migration, which relies on the differential propensity of workers - driven by ability or geography - to migrate to different regions and pursue different activities. $^{8}$

Lastly, our paper contributes to a literature documenting how migrants' characteristics

\footnotetext{
${ }^{6}$ Our results complement those of Bustos, Castro Vincenzi, Monras, and Ponticelli (2020), who show that the arrival of GMO soy to Brazil in the 2000s expanded local production of low R\&D sectors by releasing unskilled labor from agriculture. We take productivity growth as given and focus instead on how spatial labor mobility shaped comparative advantage within agriculture since the 1950s.

${ }^{7}$ In a Heckscher-Ohlin framework, Courant and Deardorff (1992) show that, if one factor of production is unevenly distributed across otherwise homogeneous regions within a country, aggregate comparative advantage can arise in the sector that uses that factor more intensively. In our framework, an uneven allocation of a single factor might affect aggregate comparative advantage depending on the distribution of natural advantages across regions.

${ }^{8}$ Burchardi, Chaney, and Hassan (2019) show that the nationality of international migrants is a determinant of the sources and destinations of FDI across US counties. Likewise, Cardoso and Ramanarayanan (2019) and Bonadio (2020) show that international migration increases international trade flows in Canada and in the US.
} 
shape their impact on the economy. ${ }^{9}$ Studying a population resettlement program in Indonesia, Bazzi, Gaduh, Rothenberg, and Wong (2016) show that differences in land suitability between origin and destination drive migrants' performance upon resettlement. Olmstead and Rhode (2011) document the role of geography and migration in the expansion of different crops in the United States. Arkolakis, Lee, and Peters (2018) study the impact of migrants on the technological frontier in the U.S. in the 19th century. ${ }^{10}$ Our contribution to this literature is twofold. First, we provide a new set of measurements relating the productivity of migrants to their origin. Second, different from these papers, we embed this heterogeneity into a quantitative general equilibrium framework to measure how it alters the incentives to trade.

\section{The March to the West}

The West of Brazil is nowadays one of the World's major agricultural powerhouses, whose agricultural exports are comparable to those large countries like Mexico and India. This status, however, came rather recently: As Figure 1 shows, the 1950s mark an inflection point in the evolution of Brazil's West. The share of Brazil's population living there remained around 7 percent before the 1950s, but it has doubled since then. Likewise, the share of agricultural land employed in the West increased by 12 percentage points, and the share of value added in agriculture generated there increased by 20 percentage points. The sequence of maps in Figure 2 shows the area we term the West in a red contour and displays its uneven settlement, in which population grew fastest in regions close to the East. ${ }^{11}$

The Onset of the March. Until the 1950s, Brazil's population had been historically concentrated in its eastern shores, mirroring economic development. The economy was organized mostly around export-oriented commodities such as sugarcane, coffee, and cotton, which benefited from easy access to ports located along the Atlantic coast. Two noteworthy excep-

\footnotetext{
${ }^{9}$ Several papers have documented the role of migrants' knowledge on the production patterns of host regions. Sabel, Fernandez-Arias, Hausmann, Rodriguez-Clare, and Stein (2012) describe their role in the formation of new export sectors in Latin America. Other examples include the diffusion of crops during the Columbian Exchange (Crosby, 1973), the introduction of new varieties of wheat in the northeast of the US in the 19th century (Olmstead and Rhode, 2008), the introduction of wheat in North Africa during the diffusion of Islam (Watson, 1983), and the production of flowers by Dutch refugees in England in the late 16th century (Scoville, 1951).

${ }^{10}$ Other recent work, including de la Roca and Puga (2017), Becker, Grosfeld, Grosjean, Voigtlander, and Zhuravskaya (2020) and Sviatschi et al. (2018), has shown that a migrant's past environment shapes his future learning and productivity.

${ }^{11}$ Brazilian States are officially divided in five broad regions based on socioeconomic and geographic features: Central-West, North, Northeast, Southeast, and South. Our analysis focuses on the occupation of the Central-West and the North, which we label the West for simplicity.
} 
tions were gold extraction in the state of Minas Gerais during the 18th century and rubber exploitation in the Amazon in the late 19th century. Beyond that, poor access to the interior severely limited economic activity there (Baer, 2001).

The March to the West began in the 1940s, when urbanization and demographic transition took off in Brazil. Concerned with food security and the population pressure in urban centers of the southeast, Getulio Vargas, the president at the time, initiated a large-scale project to occupy the Central-West region; he named the project the "March to the West". Part of the project aimed at changing Brazilians' perceptions about the West via public information campaigns, proclaiming for example that "the true sense of Brazilianness is the March to the West" (e.g., see Appendix Figure A.1 and Vargas, 1938). Other parts of the project consisted in launching expeditions to the West, investing in expanding and improving railroads, and creating institutions to establish new agricultural colonies (Villas Bôas and Villas Bôas, 1994). ${ }^{12}$

While Getulio Vargas' government gave the occupation of the West its initial thrust, it was not until the 1960s, when successive governments undertook larger investments in infrastructure to occupy the interior of Brazil, that the migration to the West became a large scale phenomenon.

The Progress of the March. The next major step of the March occurred in 1964, when the president Juscelino Kubitschek moved the Brazilian capital from the coastal city of Rio de Janeiro to Brasília, a newly constructed city in the Central-West region. Complementing this political decision, the government built a series of new highways connecting the new capital to ports and cities along the coast. ${ }^{13}$

Between the 1960s and the 1980s, a military dictatorship in Brazil expanded Kubitschek's projects as to further integrate the North of Brazil. The government invested in new roads under a new national transportation plan (Plano Nacional de Viação), granted land to agricultural colonization companies, and created a free economic zone focused on assembly plants in Manaus, a city located along the Amazon river. ${ }^{14}$ Alongside these investments

\footnotetext{
${ }^{12}$ In 1941, Getulio Vargas launched the first expedition to the west called "Roncador-Xingu". The goal of this expedition was to chart unpopulated regions in the interior of Brazil that were amenable to the construction of new cities. To complement this expedition, in 1943 the government created the Fundação Brasil Central (FBC), an institution charged with creating new population nuclei in the Western and Central region of Brazil. FBC was also tasked with coordinating the construction of a railroad in Tocantins to cross the center of Brazil, near Brasilia.

${ }^{13}$ See Morten and Oliveira (2016) and Bird and Straub (2020) for a detailed description of the roads that were constructed during this period to connect Brasília to peripheral regions.

${ }^{14}$ Many of the transportation investments and the land settlements during the military government were part of the federal government's regional development program for the Amazon (POLOAMAZONIA) (Browder, Pedlowski, Walker, Wynne, Summers, Abad, Becerra-Cordoba, and Mil-Homens, 2008). POLONOROESTE, a regional development project that received financing and development assistance from
} 
in infrastructure, the Brazilian agricultural research institute EMBRAPA - founded in the 1960s - expanded its research on the adaptation of crops to regions closer to the tropics. An emblematic result of this effort was the adaptation of soybeans to tropical areas (Nehring, 2016; Sabel, Fernandez-Arias, Hausmann, Rodriguez-Clare, and Stein, 2012; Amann, Azzoni, and Baer, 2018). ${ }^{15}$

Spurred by these public investments, the March progressed against the backdrop of spectacular economic growth, structural transformation out of agriculture, and continued urbanization, especially in the Southeast. But as Brazil entered a decade-long period of economic depression and hyperinflation in the 1980s, the cycle of large-scale investments in infrastructure that started in the 1950s came to a halt.

Knowledge and the Origin of Workers during the March. The knowledge of migrants has driven the expansion of new economic activities in several historical episodes (Olmstead and Rhode, 2008; Scoville, 1951; Watson, 1983). Sabel, Fernandez-Arias, Hausmann, RodriguezClare, and Stein (2012), p.181 document that this was also the case in Brazil during the 20th century, where gauchos, migrants from the South of Brazil, led the expansion of soybeans in the West:

The first movers had some experience with these crops in the southern part of Brazil, a region with a favorable climate and adequate conditions for soybean agriculture[...] Such experience and technical capabilities allowed them to experiment with soybean cultivation in other regions of the country at a time when international markets started to demand higher volumes of soybeans.

Additional anecdotal evidence points to this mechanism also being present in the westward expansion of other crops, such as coffee. For example: "The new amazonian experience with the "black gold" is the result of the entrepreneurship of migrants coming from Paraná, Minas Gerais and Espírito Santo [...] Farmers from Paraná and Minas Gerais brought arabica coffee to the region and farmers from Espírito Santo brought canephora coffee (i.e., robusta), which they cultivated in their region of origin." Marcolan and Espindula (2015), p. 13. ${ }^{16}$

the World Bank, focused on the forest area of Rondonia, near the Bolivian border (World Bank, 1981).

${ }^{15}$ Pellegrina (2020) analyzes the general equilibrium impact of the expansion of soybeans to tropical areas during the 1970s. Bustos, Caprettini, and Ponticelli (2016) show that the arrival of new varieties of soybeans in the late 1990s released labor from agriculture and contributed to structural change in Brazil.

${ }^{16} \mathrm{~A}$ cursory inspection of our migration data suggests that migration patterns are consistent with this idea. For instance, in the municipality of Sorriso, the largest producer of soybean in the West today, 26 percent of the labor force employed in soy comes from from Rio Grande do Sul, the state with the highest soybean output per farmer in the East. The data also bears this out for coffee, as Marcolan and Espindula (2015) suggest. In the State of Rondônia, the West's leading producer of robusta, which is a higher quality bean, accounts for 20 percent of production. The main origin of immigrant farmers in Rondônia is the State 
The fact that Brazilian farms are usually managed by small teams of workers - even farms having large acreage - is also suggestive of the important role of knowledge in the organization of production. In particular, the average number of workers per farm in the West is 3.5, with small variations across municipalities: in the 1st decile there are 2.5 average workers per farm; in the 10th decile, 4.5. Average land holdings, in contrast, vary substantially: in the 1st decile, farms have 40 hectares on average, whereas in the 10th decile they have an average of 650. Most farmers in the region, moreover, own and manage their farms. According to data from the agricultural census of 2006, approximately 90 percent of farm managers are land holders, as opposed to externally hired managers. Consistent with such numbers, the demographic census of 2010 indicates that 42 percent of agricultural workers classify themselves as a manager (as opposed to 19 percent of workers in services).

In summary, a wide range of factors promoted worker migration to the West: changes in migration and trade costs associated with the construction of roads and the federal government's propaganda, reductions in the price of land associated with land grants, productivity shocks associated with the adaptation of new crops, and the existing knowledge of workers to take advantage of them. The spatial economy model that we formulate will incorporate the influence of all these different shocks on the evolution of the economy.

\section{$3 \quad$ Data and Motivating Facts}

This section provides a brief overview of our data set and presents three empirical facts about migration and comparative advantage that guide our modeling choices. The first two facts describe aggregate patterns related Brazil's export specialization and the migration of workers to the West. The third fact shows how farmers' income and choices relate to agricultural activity in their region of origin. ${ }^{17}$

\subsection{Data sources}

We collect data from various sources to construct a panel with information about employment, migration, gross output, and domestic and international trade for Brazil between 1950 and 2010. Our data contains 133 meso-regions, 26 States, ${ }^{18}$ two countries (Brazil and the

of Espírito Santo, where robusta accounts for 30 percent of coffee output. A much smaller share comes from Eastern states specialized in arabica beans. We find similar patterns for cacao and sugarcane. We examine this relation rigorously in Fact 3.

${ }^{17}$ Appendix A provides a detailed description of our data set and Appendix B collects additional information and robustness tests related to our motivating facts.

${ }^{18}$ Meso-region is a formal political boundary defined by the Brazilian statistical bureau, IBGE, that combines municipalities according to similarities in their economic activity and labor markets. Previous re- 
rest of the world), and 13 economic activities (11 agricultural activities, manufacturing, and services). ${ }^{19}$

To measure migration flows and incomes, we use state-level migration and employment variables coming from decadal Brazilian demographic censuses from 1950 until 2010. For 1970 onward, we have micro-data at the worker level. A key feature of our micro-level data is that we observe, along with migration variables, a worker's economic activity and income.

We collect measures of gross output by meso-region and agricultural activity from Produção Agrícola Municipal (PAM) and Brazilian agricultural censuses. For non-agricultural activities, we use value added data from Instituto de Pesquisa Economica e Aplicada (IPEA) and generate gross output using value-added shares from WIOD. We adjust the level of value added by sector in Brazil to match the aggregate values reported in UN National Accounts. For the rest of the world, measures of gross output and value added come from FAO-STAT and UN National Accounts. We also include international trade flows from FAO, and measures of domestic trade flows between Brazilian states coming from Brazilian statistical yearbooks and Vasconcelos (2001). Lastly, we bring in data on land use and total labor employment for Brazil from IPEA and for the rest of the world from FAO.

\subsection{Facts about Migration and Comparative Advantage}

Fact 1: Since the 1950s, Brazil's aggregate exports have specialized in crops that the West exports more intensively than the East. Throughout the paper, we use relative bilateral exports (RBE) to describe the changes in a region's patterns of specialization. Given a common reference destination, which we take to be the rest of the world, we compute the specialization of region $i$ in activity $k$ (relative to crop $k^{\prime}$ and region $i^{\prime}$ ) as follows:

$$
R B E_{i i^{\prime}, k k^{\prime}} \equiv \frac{X_{i F, k} / X_{i^{\prime} F, k}}{X_{i F, k^{\prime}} / X_{i^{\prime} F, k^{\prime}}}
$$

where $X_{i j, k}$ are $i^{\prime} s$ exports to $j$ in activity $k$. This index of relative bilateral exports is a useful indicator of comparative advantage for two main reasons. First, it is defined for pairs

search has also employed micro-regions, which are geographically more disaggregated (see, for example, Adão (2015)). Unfortunately, it is difficult to create a consistent panel of micro-regions starting in 1950 because new micro-regions were created, while existing ones changed boundaries. To strike a balance between consistency over time and geographic disaggregation, we therefore constructed our data set at the mesoregion level. At a higher level of aggregation, Brazil currently has 27 states, one of them that represents the federal district, which was created after the construction of Brasília. We merged the current federal district to a meso-region in the state of Goias to ensure that state boundaries are consistent over time.

${ }^{19}$ The 11 agricultural activities are: banana, cacao, coffee, cotton, corn, cattle, rice, soy, sugarcane, tobacco and a residual agricultural activity which we call "rest of agriculture". Our manufacturing sector also includes other tradeables, such as mining. 
of regions and activities, as is the standard definition of comparative advantage based on autarky relative costs. Second, by fixing a destination market as reference, it focuses on supply-side sources of specialization. ${ }^{20}$

In Table 1, we apply this measure for each activity $k$ in our data, fixing $i=$ Brazil, $i^{\prime}=$ Rest of the World (F), and $k^{\prime}=$ Manufacturing. We sort crops by the intensity with which Brazil's West's specializes in them in the year 2010, for which we have exports data by Brazilian region. The table shows that by 2010, Brazil is intensively specialized in several commodities relative to ROW, among them coffee and soybean. Leading to 2010, however, Brazil's specialization changed substantially. For Brazil as a whole, RBE of commodities such as soy, beef, and corn - in which the West specializes - grew rapidly, while it plummeted for traditional ones such as coffee, cacao, and banana. And along with these changes in relative specialization came a large change in Brazil's export basket, in which these three crops now account for approximately 13 percent of total exports and 40 percent of agricultural exports.

Fact 2: Across regions and activities in the West, the participation of Eastern migrants was large and varied substantially. The dramatic rise of the West was driven, in no small part, by migration from the East: On average Eastern migrants account for 30 percent of the West's workforce in 2010. This share, however, varies substantially across locations and activities. Focusing on a statistic which in our theory will measure the impact of migration, Figure 3 shows that the share of non-migrants in employment is quite low for some activities, especially for soy, both in 1980 and 2010. Within activities, there is also large variation in the non-migrant share across regions, as shown in Figure 4. These two facts suggest that migration had a differential impact across regions and crops, and that workers followed clear sorting patterns.

Fact 3: Upon migration, farmers originating in regions with high employment in an agricultural activity are more likely to work in that activity and have higher income than other migrants doing so. We now compare migrants working in the same activity and destination, but who come from origins with different patterns of agricultural specialization, estimating the following regressions: ${ }^{21}$

\footnotetext{
${ }^{20}$ French (2017) shows that this measure maps to Haberler's definition of comparative advantage, which is based on autarky opportunity costs, if trade costs are not sector-country specific. Appendix Table A.1 shows that using instead the Revealed Comparative Advantage measure developed by Balassa (1965) provides a qualitatively similar evolution in the patterns of comparative advantage. See French (2017) and Costinot, Donaldson, and Komunjer (2012) for a detailed discussion of different empirical measures comparative advantage and how they connect to trade models.

${ }^{21}$ Throughout the paper, we focus on identifying the knowledge of migrants in the agricultural sector. We do so for several reasons, beyond the outsize importance of Brazil's agriculture in the world. Most importantly, the census provides quite granular sector definitions within agriculture, which allows us to
} 


$$
\begin{aligned}
& \log \text { income }_{i j, k t}=\iota_{j, k t}^{I}+\iota_{i j, t}^{I}+\alpha^{I} \log \text { workers }_{i, k t-1}+\epsilon_{i j, k t}^{I}, \\
& \log \text { workers }_{i j k t}=\iota_{j, k t}^{W}+\iota_{i j, t}^{W}+\alpha^{W} \log \operatorname{workers}_{i, k t-1}+\epsilon_{i j, k t}^{W},
\end{aligned}
$$

where $i$ indexes the origin region, $j$ the destination region, $k$ the agricultural activity and $t$ the year. To gain precision, we stack data for the years $t=2000$ and $t=2010$. With an eye toward our modeling strategy later, we use a thirty-year lag as our measure of workers ${ }_{i, k t-1} \cdot{ }^{22}$ To avoid the inclusion of the same farmer in both sides of the equation, we exclude nonmigrants from our sample.

In equation (2), $\alpha^{I}$ measures the association between farmers' comparative advantage and the size of the workforce in the origin region. In equation (3), $\alpha^{W}$ captures how this comparative advantage translates into activity choice. By including destination and crop fixed effects $\left(\iota_{j, k t}^{W}\right.$ and $\left.\iota_{j, k t}^{I}\right)$ in our specifications, we control for any factor that is common across workers in destination $j$ and activity $k$, including natural advantages, local institutions, or price shocks. By including origin and destination fixed effects $\left(\iota_{i j, t}^{W}\right.$ and $\left.\iota_{i j, t}^{I}\right)$, we control for common factors that are origin and destination but not activity specific, such as human capital and bilateral migration costs. ${ }^{23}$

Panel A in Table 2 shows estimates of equation (2). In Column 1, an increase of 1 percent in the number of agricultural workers in the region of origin in a given activity increases the average income of workers in the destination in this same activity by 0.016 percent. This effect increases to 0.023 when we include destination-origin fixed effects (Column 2). Since origin-destination-crop cells containing zero workers are frequent in our sample, we explore three additional specifications. In Column 3 we drop observations below the bottom quartile in the distribution of workers ${ }_{i j, k t-1}$. As one would expect if low values of our regressor make sampling zeros more likely, this specification increases our coefficients to 0.047. We then repeat our OLS specifications using a PPML estimator, to study the impact of bias due to

identify crop-level employment; for manufacturing, on the contrary, the sectoral classification is quite broad, especially if one is to create consistent categories across years. This is especially problematic in constructing gross output series, which we require for calibrating our model. Moreover, as discussed earlier, there is an abundance of anecdotal evidence on the diffusion of knowledge in agriculture, which we rigorously map to data here. That said, Appendix Table A.10 shows that when we focus on a sample of manufacturing workers and sectors our results broadly concur with those in this section.

${ }^{22}$ Data on a worker's meso-region of birth is unavailable. Therefore, to run the regressions in this Section, we define migration based on a workers current and previous meso-region of residence. In Appendix B, we present results based on state-level data in which we define migration based on state of birth and find similar patterns.

${ }^{23}$ Figure A.2 in the Appendix shows non-parametrically the variation that identifies $\alpha^{I}$ and $\alpha^{W}$. In both cases, a log-linear relationship provides a good approximation of the relationship between our dependent and explanatory variables. 
heteroskedasticity (Silva and Tenreyro, 2006). These alternative specifications increase our point estimates up to 0.083 percent.

Panel B shows that the elasticity of migrants' activity choice with respect to the number of farmers in the origin rises from 0.074 to 0.131 across the same specifications. In this panel, we can also include all zeros in our sample; doing so increases the coefficient to 0.165 (Column 6).

Appendix B shows that our results are largely robust across specifications in which we employ different lags for workers ${ }_{i j, k t-1}$, control for observable socioeconomic characteristics, use finer levels of geographic disaggregation, and run regressions using individual data. To provide more tangible evidence on these mechanisms, we additionally use data from the GAEZ project (IIASA/FAO, 2012), to show that similarity in crop suitability between regions is a strong predictor of migration flows. Lastly, we also show that, controlling for a series of controls and fixed effects, yields are higher in regions and crops where a larger proportion of farmers emigrate from origins with high-employment in that same crop.

This evidence thus suggests that, controlling for any factors that make workers from an origin go to a destination (e.g. distance or weather similarity) and controlling for agroclimatic and other local work conditions (such as access to inputs or Marshallian externalities), workers performance is heterogeneous. The evidence also suggests that this heterogeneity is shaped by the employment structure of the region where migrants come from.

To generate these reduced form elasticities in our spatial model as parsimoniously as possible, we assume that workers acquire activity specific knowledge in their origin region, and that this knowledge influences how they sort across destinations and activities. Doing so also rationalizes our evidence on occupational choice because workers sort into the activities they are better suited at doing. ${ }^{24}$

\section{A Model of Migration and Comparative Advantage}

In this section, building on the dynamic approach by Allen and Donaldson (2020), we develop a quantitative model of trade and migration in which comparative advantage is driven by regional productivity, land abundance, and the activity-specific knowledge of migrants. To simplify our exposition, we present a stylized version of the model and a summary definition of the equilibrium. ${ }^{25}$

\footnotetext{
${ }^{24}$ This evidence is inconsistent with a model in which individuals types are fixed and independent of their origin. Appendix B shows that such a model would tend to generate $\alpha^{W}$ equal to 1 in equation (3) and $\alpha^{E}$ equal to 0 in equation (3).

${ }^{25}$ We relegate a full description of the equilibrium and of our quantitative model, as well as the proofs to statements in this Section to Appendix C.
} 
After describing our model, we present two analytical results about the relation between migration and trade. The first result connects our paper to the literature studying the sources of comparative advantage, by showing how migration costs shape regional and national comparative advantage under free trade. The second result guides our quantitative analysis: we derive a sufficient statistic for the impact of completely limiting migration on comparative advantage, at any level of trade costs.

\subsection{Environment}

Geography and Commodities. Time is discrete and indexed by $t$. The world, $\mathcal{W}$, consists of many regions $j=1, \ldots, I$ that comprise the Home country, and of a rest of the world composite, denoted by $F$. There are $k=1, \ldots, K$ activities (or goods), and each region produces an unique variety of each good. At each time, the geography of the economy is given by a set of natural advantages, a matrix of iceberg trade costs, a matrix of iceberg bilateral migration costs, and a land endowment: $\left\{A_{j, k t}, \tau_{i j, k t}, \mu_{i j, k t}, H_{j, t}\right\}$. We omit time indexes whenever unnecessary for our presentation.

Technology. In each region $j$, representative firms aggregate varieties of good $k$ into aggregate good output with constant elasticity of substitution $\eta_{k} \cdot{ }^{26}$ Good output is likewise aggregated into final output, with constant expenditure shares $a_{k}$. Only varieties are traded. Correspondingly, the price index for activity $k$ in region $j$ is given by $P_{j, k t}^{\left(\eta_{k}-1\right) / \eta_{k}}=$ $\sum_{i \in \mathcal{W}}\left(\tau_{i j, k t} p_{i, k t}\right)^{\left(\eta_{k}-1\right) / \eta_{k}}$, while that of final output is $P_{j, t}=\prod_{k=1}^{K} P_{j, k t}^{a_{k}}$.

To produce $q$ units of good $k$ in region $i$, a worker with knowledge $s$ combines land $l$ and final output $m$, according to:

$$
q_{j, k}=A_{j, k}\left(s^{1-\gamma_{k}} l^{\gamma_{k}}\right)^{\alpha_{k}} m^{1-\alpha_{k}}
$$

where $\alpha_{k}$ measures the share of value-added in production and $\gamma_{k}$ measures the land intensity of good $k$. For non-agricultural activities, we set $\gamma_{k}=0$.

Demography and Preferences. People live two periods, young and old. An adult at time $t$, upon observing her knowledge, chooses an activity-location pair and then spawns one

\footnotetext{
${ }^{26}$ For simplicity, we adopt an Armington formulation within activities $k$. Our focus is on intersectoral comparative advantage, which is still governed by observable differences in relative costs. Both our theoretical and quantitative results would be identical if we adopted instead a multisector Eaton and Kortum (2002) formulation. We do not adopt the formulation in Sotelo (2020), which sets $\eta_{k} \rightarrow \infty$ for agricultural goods, to keep our simulations quantitatively tractable, since our model features dynamics and a large number of goods and regions.
} 
child. To simplify matters, we work with non-altruistic parents. Let $L_{j t}$ denote the adult population at time $t$ in region $j$.

Adult workers born in $t-1$ maximize welfare by choosing where to live and in which activity to work at time $t$ :

$$
\max _{j, k} W_{i j, k t} \varepsilon_{j, k t}
$$

where preference shocks are drawn i.i.d from $G(\varepsilon)=\exp \left(-\varepsilon^{-\kappa}\right)$ and $W_{i j k t}$ is the systematic component of welfare, given by:

$$
W_{i j, k t}=\frac{w_{j, k t} s_{i, k t}}{\mu_{i j, k t} P_{j, t}},
$$

where $w_{j, k t}$ is the wage per efficiency unit of labor (i.e., the return to a unit knowledge), $\mu_{i j, k t}$ represents iceberg migration costs that reduce utility directly, and $P_{j, t}$ is the price index of final output consumption in destination region $j$. Reflecting our empirical findings, $s_{i, k t}$ is a farmer's knowledge to produce in activity $k$, which depends on the region she comes from. ${ }^{27}$ Workers can migrate within the Home country, but not between Home and Foreign.

Knowledge Endowment. A child born in $i$ at time $t-1$ is characterized by a vector of activity-specific productivities, $s_{i, k t}$, which depends on the employment structure in the region where she is born, $s_{i, k t}=s\left(L_{i, k t-1}\right)$. In particular, motivated by Fact 3 in Section 3 , we assume that knowledge depends on good-specific employment in the origin region through the following functional form: ${ }^{28}$

$$
s_{i, k t}=\bar{s}_{k} L_{i, k t-1}^{\beta}
$$

\subsection{Equilibrium}

In what follows, we denote by $c_{j, k t}$ the cost of a unit of the input bundle, given by $c_{j, k t}=$ $\bar{c}_{k}\left(w_{j, k t}^{1-\gamma_{k}} r_{j, t}^{\gamma_{k}}\right)^{\alpha_{k}} P_{j t}^{1-\alpha_{k}}$, where $w_{j, k t}$ are efficiency wages, $r_{j, t}$ are land rents and $\bar{c}_{k}$ is a technology constant.

\footnotetext{
${ }^{27} \mathrm{~A}$ broader interpretation of $\mu_{i j k}$ is that good-specific knowledge can be lost in migration, if it is specific to agro-climatic conditions in the origin.

${ }^{28}$ This formulation captures in a transparent way the relation between heterogeneity and migrant origin from Fact 3. Since our regressions include origin-destination fixed effects, it is unclear whether our parameterization of $s\left(L_{i, k t-1}\right)$ should depend on the level or the share of agricultural employment in the origin region. Our formulation builds on a large literature emphasizing scale effects in productivity, both in growth and international economics (Ramondo, Rodríguez-Clare, and Saborío-Rodríguez, 2016). We show later on that our quantitative results remain almost unchanged when considering an alternative formulation in which knowledge depends on agricultural employment shares, $s_{i, k}=\left(L_{i, k t-1} / L_{i, t-1}\right)^{\beta}$. A substantially more involved alternative would introduce forward-looking workers who make human capital accumulation decisions. As we discuss below, the key to most of our quantitative results is that the model captures the patterns of sorting across crops that we observe in the data, which our current formulation does.
} 
As is standard in an Armington formulation, the share of region $j^{\prime} s$ sector $k$ expenditure going to origin $i$ is given by $\pi_{i j, k t}=\left(c_{i, k t} \tau_{i j, k t} / A_{i, k t}\right)^{1-\eta} / P_{j, k t}^{1-\eta}$. Likewise, optimal worker sorting gives the share of workers from $i$ choosing to work in region $j$ and activity $k$ :

$$
\lambda_{i j, k t}=\frac{W_{i j, k t}^{\kappa}}{\Xi_{i, t}^{\kappa}}
$$

where $W_{i j, k t}$ is given by equation (4) and $\Xi_{i, t}^{\kappa} \equiv \sum_{j} \sum_{k} W_{i j, k t}^{\kappa} \cdot{ }^{29}$ We define the effective units of labor migrating from $i$ to region $j$, activity $k$ as

$$
E_{i j, k t} \equiv s_{i, k t} \lambda_{i j, k t} L_{i, t-1}
$$

To close the model, we assume that land rents are paid to local landowners. Total expenditure in region $j$ reflects final and intermediate expenditure:

$$
X_{j, t}=\sum_{k} w_{j, k t} E_{j, k t}+r_{j, t} H_{j, t}+\sum_{k=1}^{K}\left(1-\alpha_{k}\right) Y_{j, k t},
$$

where $Y_{j, k t}$ denotes revenues in activity $k, Y_{j, k t}=\sum_{i} \pi_{j i, k t} a_{k} X_{i, t}$, and $E_{j, k t}=\sum_{i} E_{i j, k t}$ is the supply of efficiency units there.

Equilibrium. Given the geography and initial labor allocations, $\left\{L_{i, k 0}\right\}_{i k}$, a general equilibrium is a sequence of factor prices and labor allocations $\left\{r_{j, t}, w_{j, k t}, E_{j, k t}\right\}_{j k t}$, such that, for each region $j$ and activity $k$ and time $t$ : (i) Workers choosing to migrate to $j, k$ satisfy (6) given (5) and factor prices, (ii) the market for efficiency units of labor clears, (iii) land markets clear for region $j$, and (iv) trade is balanced.

Discussion. Characterizing the properties of equilibria in spatial models with multiple activities is a current area of work, and, to the best of our knowledge, there are no general sufficient conditions that guarantee uniqueness. That said, our trade model satisfies the conditions for uniqueness laid out by Kucheryavyy, Lyn, and Rodríguez-Clare (2016) in the case of free trade. Moreover, a single-activity version of this model satisfies the conditions for period-by-period uniqueness laid out by Allen and Donaldson (2020), since our model features no contemporaneous externalities in labor supply. In these special cases, it follows that, given the economy's initial conditions, the equilibrium path is unique for all $t$.

\footnotetext{
${ }^{29}$ In bringing the model to data in Section 5 , migration costs $\mu_{i j, k t}$ or knowledge $s_{i, k t}$ act together to rationalize migration data. Hence we will be able to separate the contribution of skill specificity to what would otherwise look as migration costs.
} 
In a steady state our economy features contemporaneous externalities coming from the effect of equilibrium labor allocations on worker heterogeneity. Because these externalities operate by increasing the effective supply of workers, they are distinct from Marshallian externalities or scale effects in models of imperfect competition, which instead raise the demand for labor (Bartelme, Costinot, Donaldson, and Rodríguez-Clare, 2019; Kucheryavyy, Lyn, and Rodríguez-Clare, 2016). Although the mechanism is different, equilibrium multiplicity is also a possibility in our environment. On the one hand, a closed economy lacking internal geography will feature such corners, provided $\beta$ is large enough relative to the elasticity of substitution between activities. On the other hand, in the limit in which Brazil is a small open economy, any region-activity pair with positive productivity will have positive employment, so we can rule out corners with zero employment. ${ }^{30}$ As long as at least one region produces a crop, next period there will be workers willing to go to any other region to do it, given idiosyncratic shocks (Appendix C).

\subsection{How Migration Costs Shape Comparative Advantage}

We begin the analytical discussion of our model by studying how migration shapes comparative advantage, that is, autarky opportunity costs. In doing so, we connect to a long literature studying how a country's cost structures relates to trade patterns. The general equilibrium interactions between opportunity costs and migration in our model are, unfortunately, too complex to characterize them as explicit functions of exogenous parameters. We therefore derive analytical results using a pared down version of our model. We let labor be the only productive factor $\left(\gamma_{k}=0, \forall k\right)$ and impose equal value-added shares and trade elasticities across activities (i.e., $\alpha_{k}=\alpha$ and $\eta_{k}=\eta, \forall k$ ). Finally - in this section only we zoom in on the role of spatial mobility by assuming that workers are born with a type and only choose where to live.

\subsubsection{Autarky opportunity costs}

A classic definition of comparative advantage due to Haberler (1930) states that region $i$ has a comparative advantage in activity $k$ (relative to region $j$ and activity $k^{\prime}$ ) if $i^{\prime}$ s autarky opportunity cost of producing $k$ in terms of $k^{\prime}$ is lower than that of $j .{ }^{31}$ To study these

\footnotetext{
${ }^{30}$ In defining a small economy, we follow Alvarez and Lucas (2007) (see Appendix C.2). Intuitively, we study the limit of our economy as we let the labor endowments of each region in the Home economy vanish, while keeping constant for each region the ratios of total labor to sectoral productivity and total land..

${ }^{31}$ The application and generalization of this definition in different comparative advantage models is discussed by Deardorff (2005). French (2017) applies it to recent quantitative frameworks, such as the one we use, but abstracts from internal geography.
} 
opportunity costs, we fix $j=F$ and consider two different scenarios, in both of which region $i$ 's trade costs with any other region are prohibitive.

First, in the case in which internal migration costs are prohibitively high, $\mu_{i j, k} \rightarrow \infty$, $\forall i \neq j$, stating that $i$ has a comparative advantage in $k$ (relative to $k^{\prime}$ and $F$ ) is equivalent to the following inequality:

$$
\left(\frac{s_{i, k} L_{i, k}^{0}}{s_{i, k^{\prime}} L_{i, k^{\prime}}^{0}}\right)^{\alpha} \frac{A_{i, k}}{A_{i, k^{\prime}}}>\left(\frac{s_{F, k} L_{F, k}^{0}}{s_{F, k^{\prime}} L_{F, k^{\prime}}^{0}}\right)^{\alpha} \frac{A_{F, k}}{A_{F, k^{\prime}}}
$$

where the superscript 0 denotes predetermined variables.

Second, when internal migration is costless, $\mu_{i j, k}=1, \forall i, j, k$, the same statement is equivalent to:

$$
\left(\frac{\mathcal{S}_{H, k}}{\mathcal{S}_{H, k^{\prime}}}\right)^{\alpha} \frac{A_{i, k}}{A_{i, k^{\prime}}}>\left(\frac{\mathcal{S}_{F, k}}{\mathcal{S}_{F, k^{\prime}}}\right)^{\alpha} \frac{A_{F, k}}{A_{F, k^{\prime}}},
$$

where $\mathcal{S}_{H, k} \equiv \sum_{i} s_{i, k} L_{i, k}^{0}$.

Expressions (8) and (9) reveal that knowledge acts as a productivity shifter in our model and that migration determines its allocation. When migration costs are prohibitive, the knowledge available in a location comes solely from workers born there. With free mobility, in contrast, knowledge from all the country is available to each region, as reflected by the term $\mathcal{S}_{H, k}$, which measures the aggregate effective supply of workers at Home, for activity $k$. Migration therefore undoes any exogenous correlation between local worker productivity and local natural productivity, and its impact on regional comparative advantage is ambiguous: it will strengthen regional comparative advantage if high knowledge workers were born in low productivity locations, but it will weaken it the opposite is true. In our application, the West's rapid productivity growth in certain activities led migration to strengthen comparative advantage. ${ }^{32}$

\subsubsection{Regional and Aggregate Trade Specialization}

How do autarky opportunity costs shape realized free-trade specialization, i.e., when $\tau_{i F, k}=$ $\tau_{F i, k}=1$ ? We now turn to study the conditions under which $R B E_{i F, k k^{\prime}}>1$. It is straightforward to show that when migration costs are prohibitive, autarky opportunity costs fully determine trade specialization. This result is intuitive, since in this case a region really is simply a separate economy; the elasticity of trade flows to autarky costs is exactly

\footnotetext{
${ }^{32}$ Allowing workers to choose over activities, as we do in our main model, will tend to strengthen the correlation between natural advantage and comparative advantage. The reason is that sectoral productivity differences within a region will induce differences in wages, which in turn drive the equilibrium labor allocation.
} 
$(\eta-1)[1+\alpha(\eta-1)]^{-1}$ (see Appendix Equation (51)).

Under free internal migration, however, this is no longer the case. $R B E_{i F, k k^{\prime}}>1$ is equivalent to the following relation between fundamentals:

$$
\left[\left(\frac{\mathcal{S}_{H, k} \mathcal{A}_{i, k}}{\mathcal{S}_{H, k^{\prime}} \mathcal{A}_{i, k^{\prime}}}\right)^{\alpha}\left(\frac{A_{i, k}}{A_{i, k^{\prime}}}\right)\right]^{\frac{\eta-1}{1+\alpha(\eta-1)}}>\left[\left(\frac{\mathcal{S}_{H, k} \mathcal{A}_{F, k}}{\mathcal{S}_{H, k^{\prime}} \mathcal{A}_{F, k^{\prime}}}\right)^{\alpha}\left(\frac{A_{F, k}}{A_{F, k^{\prime}}}\right)\right]^{\frac{\eta-1}{1+\alpha(\eta-1)}}
$$

where $\mathcal{A}_{i, k} \equiv A_{i, k}^{\kappa \frac{\eta-1}{1+\kappa+\alpha(\eta-1)}} / \sum_{h} A_{h, k}^{\kappa \frac{\eta-1}{1+\kappa+\alpha(\eta-1)}} \cdot 33$ This inequality provides three insights into specialization. First, just like with opportunity costs, the impact of migration on trade specialization in equation (10) is ambiguous and captured by $\mathcal{S}_{H, k}$. Second, direct comparison of expressions (9) and (10) reveals that autarky opportunity costs do not fully determine specialization, since the term $\mathcal{A}_{i, k}$ is absent from the costs inequality (9). The reason is that, with free migration, region $i$ competes with other regions in its own country for the same workers, and the relative payments this region can offer depends on its sales. As opposed to autarky, having a high productivity relative to the rest of the country under free trade -i.e., a high $\mathcal{A}_{i, k}$ - attracts a larger labor supply and reduces marginal costs. Thus the relation between autarky opportunity costs and free trade specialization could even be overturned if a region is relatively productive in a crop when compared in isolation to $F$, but not relative to the rest of the country. Third, since aggregate knowledge $S_{H, k}$ is shared by all regions in Home, it does not shape comparative advantage nor trade flows across regions within the same country.

Turning to country-wide specialization, when internal migration costs are prohibitively high, autarky opportunity costs fully determine aggregate specialization, just as in the regional case (see Appendix Equation (57)). Specifically, the Home economy specializes in exporting sector $k$ if a weighted average of its autarky marginal costs is low enough.

But under free internal migration, $R B E_{H F, k k^{\prime}}>1$ is equivalent to

$$
\left(\frac{S_{H, k}}{S_{H, k^{\prime}}}\right)^{\frac{\alpha(\eta-1)}{1+\alpha(\eta-1)}} \frac{\sum_{i \in H} \mathcal{A}_{i, k}^{\frac{\alpha(\eta-1)}{1+\alpha(\eta-1)}} A_{i, k}^{\frac{\eta-1}{1+\alpha(\eta-1)}}}{\sum_{i \in H} \mathcal{A}_{i, k^{\prime}}^{\frac{\alpha(\eta-1)}{1+\alpha(1)}} A_{i, k^{\prime}}^{\frac{\eta-1}{1+\alpha(\eta-1)}}}>\frac{\mathcal{S}_{F, k}^{\frac{\alpha(\eta-1)}{1+\alpha(\eta-1)}} A_{F, k}^{\frac{\eta-1}{1+\alpha(\eta-1)}}}{\mathcal{S}_{F, k^{\prime}}^{\frac{\alpha(\eta-1)}{1+\alpha(\eta-1)}} A_{F, k^{\prime}}^{\frac{\eta-1}{1+\alpha(\eta-1)}}}
$$

Expression (11) shows that aggregate knowledge $\mathcal{S}_{H, k}$ also shapes aggregate specialization - an aggregation result that follows from the fact that every region within Home has equal access to knowledge. Migration again has an ambiguous impact on comparative advantage, now in the aggregate. If, on average, labor was initially allocated to regions where labor

\footnotetext{
${ }^{33}$ The exponent of $A_{i, k}$ in $\mathcal{A}_{i, k}$ increases in $\kappa$. As we let $\kappa \rightarrow \infty$ workers become homogeneous and therefore more elastic to wage differences across regions. In this limit, the competition for workers has its largest effect on marginal costs.
} 
productivity is low, migration will undo that correlation, and amplify relative productivity differences. More broadly, as in Courant and Deardorff (1992) an uneven distribution of labor can generate comparative advantage; the difference is that in our framework it comes from the assignment of a single factor across heterogeneous regions (rather than two factors across homogeneous regions).

\subsection{A Sufficient Statistic}

To interpret our quantitative results, we introduce a statistic that summarizes the impact of migrants on specialization. We return to our framework where both location and activity are worker's choices, but focusing on a small open economy.

Proposition 1. Assume that Home is a small open economy, and that $\eta_{k}=\eta, \gamma_{k}=\gamma \forall k$. The change in specialization when migration to region $i$ becomes prohibitively costly, $\mu_{i j, k}^{\prime} \rightarrow \infty$, $\forall j \neq i$ is given by:

$$
\frac{X_{i F, k} / X_{i F, l}}{X_{F F, k} / X_{F F, l}}=\left(\mathcal{E}_{i i, k} / \mathcal{E}_{i i, l}\right)^{-\frac{\alpha(1-\gamma)(1-\eta)}{1+\kappa+\alpha(1-\gamma)(\eta-1)}},
$$

where $\mathcal{E}_{i j, k}$ is the share of workers from $i$ in $j^{\prime} s$ effective labor force in activity $k$, i.e., $\mathcal{E}_{i j, k}=E_{i j, k} / E_{j, k}$, and $\hat{z}$ denotes proportional changes in variable $z$.

The proposition shows that the relative share of domestic workers in total effective labor supply is a sufficient statistic for the impact on specialization of limiting migration from all other regions. This result is analogous to the well-known result by Arkolakis, Costinot, and Rodriguez-Clare (2012) on the gains from trade. In our model, exposure varies across crops and regions for two reasons. The first is worker heterogeneity, which makes workers with higher knowledge $s_{i, k}$ account for a larger share of effective employment in destinationactivity pair $j, k$. The second is migration costs that are origin-destination-activity specific. Without these two forces, exposure shares are equalized within region $j$, and migration has no impact on intersectoral specialization.

The results of this section provide a sharp characterization of the role of migration costs in shaping comparative advantage and trade patterns But there are two caveats in their application. First, observed changes in migration costs are finite. Second, sectors have different trade elasticities, while land and intermediate-input intensities are additional drivers of comparative advantage. Bearing such caveats in mind, we deploy these insights throughout the rest of the paper, which quantitatively evaluates the impact of observed changes in migration costs. 


\section{Taking the Model to Brazilian Data}

To simulate the impact of the migration to the West, we need to measure production and technology parameters, trade and migration costs, and worker heterogeneity. We map the model to Brazil's economy in 1950, 1980, and 2010, thus setting a time period to 30 years. We thus start early enough to observe the transformation of Brazil due to the March, but within the constraints imposed by data quality and availability. In this section, we provide a summary of our calibration and results, but first we describe the additional features that we introduce in the model to bring it to the data. ${ }^{34}$

\subsection{The Quantitative Model}

Relative to the model presented in the last section, we add three elements. First, we bring in two-tiered CES preferences: agents choose first how much to consume of services, agriculture, and manufacturing $(s=S, A, M)$, with an elasticity of substitution $\sigma$, and then choose how much to consume of each activity within the agricultural sector, with an elasticity of substitution of $\sigma_{A}$. Second, we introduce a CES technology in which farmers combine efficiency labor and land, with an elasticity of substitution $\rho$ and land intensity shifter $\gamma_{k}$. Third, we endogeneize the supply of land by allowing local governments to produce land, using a decreasing returns technology that requires final output.. The profits from land development are rebated to farmers proportionally to their wages. The productivity of the technology used by local governments is $b_{j}$ and the elasticity of land supply to land rents is $\zeta .^{35}$

\subsection{Calibration}

\subsubsection{Worker heterogeneity}

The preference dispersion parameter, $\kappa$, and the worker productivity parameter, $\beta$, map to the reduced-form elasticities we estimated in Fact 3. Using equation (5), our model relates the income of migrants to the employment in the origin as follows:

$$
\log \left(\text { income }_{i j, k t}\right)=\iota_{j, k t}^{I}+\iota_{i j, t}^{I}+\beta \log L_{i, k t-1}+u_{i j, k t}^{I} .
$$

To motivate the error $u_{i j, k t}^{I}$, we posit measurement error in income. The fixed effects correspond to $\iota_{j, k t}^{I}=\kappa \log w_{j, k t}, \iota_{i j, t}^{I}=\log L_{i, t-1}$-if knowledge depends on relative employment

\footnotetext{
${ }^{34}$ In Appendix E, we include a thorough description of our calibration algorithm.

${ }^{35}$ We abstract from other forces common in the spatial economics literature, such as amenities or productivity spillovers, to provide a clear evaluation of the new mechanisms in this paper.
} 
shares - but also absorb systematic components of measurement error in income.

Analogously, we substitute equation (12) into (6) to obtain our regression for activity choice:

$$
\log L_{i j, k t}=\iota_{j, k t}^{L}+\iota_{i j, t}^{L}+\kappa \beta \log L_{i, k t-1}+u_{i j, k t}^{L},
$$

where the fixed effects correspond to $\iota_{i j, t}^{L}=\log L_{i, t-1}-\kappa\left(\log \mu_{i j, t}+\log \Xi_{i t}\right), \iota_{j, k t}^{L}=\kappa\left(\log w_{j, k t}\right.$ $\left.-\log P_{j, t}\right)$, and $u_{i j, k t}^{L}$ captures a unmeasured component migration flows or of migration costs orthogonal to the other observables and fixed effects (e.g. as in Eaton and Kortum, 2002). Our thus model gives a structural interpretation to Fact 3, and show that the estimated coefficient $\alpha^{I}$ in regression (3) measures $\beta$, while coefficient $\alpha^{W}$ in regression (2) measures $\kappa \beta$.

The estimates for $\beta$ range between 0.023 and 0.083 , and the implied values for $\kappa$ range between 1.58 and 3.26. Using quite different strategies, a few recent papers have estimated similar values of $\kappa$, which controls the elasticity of migration with respect to real wages. For example, using migration data for Brazil, Morten and Oliveira (2016) estimate a value of 1.9 and, using migration data from China, Tombe and Zhu (2019) find values between 1.2 and 1.6. ${ }^{36}$ Since $\beta$ is new to our theory, in contrast, there is no direct benchmark with which to compare it. But our results are comparable to those of sectoral scale economies (Antweiler and Trefler, 2002; Bartelme, Costinot, Donaldson, and Rodríguez-Clare, 2019) and of the effect of city size on productivity: de la Roca and Puga (2017). Henceforth, we set $\kappa=2$ and $\beta=0.04$. In robustness analysis, we also consider $\beta \in\{0,0.083\}$.

\subsubsection{Trade Costs}

We need to calibrate trade costs between regions for each activity and period, which gives a total of $134 \times 134 \times 13 \times 3$ parameters. Given the trade data we have available, this requires us to parameterize trade costs. Akin to Ramondo, Rodríguez-Clare, and Saborío-Rodríguez (2016), we assume for $i=j$, that $\tau_{i j, k t}=1$ and, for $i \neq j$, that

$$
\tau_{i j, k t}=\delta_{t}^{0}\left[\left(d_{i s t_{i j}}\right)^{\delta_{t}^{1}}\right]^{\iota_{i j}^{T}}\left[\delta_{k t}\left(\operatorname{dport}_{i}\right)^{\delta_{t}^{1}}\left(\operatorname{dport}_{j}\right)^{\delta_{t}^{1}}\right]^{1-\iota_{i j}^{T}}
$$

where $\iota_{i j}^{T}$ is a dummy variable that equals one if $i$ and $j$ belong to same country and zero otherwise, dist $t_{i j}$ is the travel distance between $i$ and $j$, and $d p o r t_{i j}$ is the minimum travel distance to the nearest port (for $j=F$, we set $\operatorname{dport}_{j}=1$ ).

\footnotetext{
${ }^{36}$ As expected, our elasticities of migration to wages are larger than those in Artuç, Chaudhuri, and McLaren (2010) and Caliendo, Dvorkin, and Parro (2019), who study migration at a higher frequency than we do.
} 
We calibrate $\delta_{t}^{0}$ to match the observed share of intra-regional trade in total domestic trade in Brazil. In particular, we construct $\sum_{s \in H} X_{s s} / X_{H H}$, where $X_{s s}$ are sales of state $s$ to itself, and $X_{H H}$ are sales of Brazil to itself. We target a domestic trade ratios of 0.7 for 1950, 0.65 for 1980, and 0.60 for 2010, which gives $\delta_{t}^{0}$ of $0.08,0.42$ and 0.58 . We choose $\delta_{t}^{1}$ so that the model matches the empirical elasticity of trade flows between states with respect to distance. For 2010, the OLS estimate of this elasticity is 1.05; for 1980, 1.25, and for 1950, 2.5 , which translates into $\delta_{t}^{1}$ of $0.22,0.25$, and 0.52 respectively. Lastly, we calibrate $\delta_{k t}$ to match Brazil's trade with the rest of the world.

\subsubsection{Technology and Preferences}

As for technology, we set the share of value added $\alpha_{k}$ to 0.30 for manufacturing, 0.55 for agriculture and 0.6 for services according to the aggregate share of value added in the World Input-Output Database. For non-agricultural activities, we set $\gamma_{k}=0$. For agriculture, we set $\rho=0.5$, which is the mid-value between Costinot, Donaldson, and Smith (2016), who assume perfect complementarity between land and labor $(\rho=0)$, and a Cobb-Douglas production function $(\rho=1)$, as in Restuccia, Yang, and Zhu (2008). Our main specification sets $\gamma_{k}=0.21$ for all agricultural activities based on Dias Avila and Evenson (2010), thus allowing for Heckscher-Ohlin forces between agriculture and manufacturing. In gauging the strength of this channel, we experiment with their input cost-shares, separating crops from cattle (0.17 and 0.32 , respectively). Lastly, we set the land supply elasticity $\zeta$ to $1.5 .{ }^{37}$

As for preferences, we set $\sigma$ to 0.4 based on Comin, Lashkari, and Mestieri (2015), $\sigma_{a}$ to 2.5 according to Sotelo (2020), $\eta_{k}$ in agriculture to 9.5 , and $\eta_{k}$ for other sectors to 5.5 following Caliendo and Parro (2015). ${ }^{38}$

Having calibrated trade costs, technology and preferences, we follow the model-inversion logic laid out by Allen and Arkolakis (2014) and calibrate $A_{j, k t}$ to match observed gross output and $b_{j, t}$ to match observed agricultural land use.

\subsubsection{Migration Costs}

With an eye toward counterfactuals, we extract a state-state component from migration costs, and break down the remainder into a state-state-activity component and geographic component that operates across meso-regions. Formally, we assume, for $i=j$, that $\mu_{i j, k t}=1$

\footnotetext{
${ }^{37}$ There is some discussion in the literature about the right elasticity of land supply over long periods of time. We pick a number in the range between Costinot, Donaldson, and Smith (2016) and Gouel and Laborde (2018).

${ }^{38} \mathrm{We}$ adjust preference shifters $\left(a_{H, k t}\right.$ and $\left.a_{F, k t}\right)$ to match country-level apparent consumption in each activity.
} 
and, for $i \neq j$, that

$$
\mu_{i j, k t}=\mu_{t}^{0}\left[\left(d_{i s t_{i j}}\right)^{\mu^{1}}\right]^{\iota_{i j}^{M}}\left[\mu_{s s^{\prime}, t} \mu_{s s^{\prime}, k t}\left(\text { dcap }_{i}\right)^{\mu^{1}}\left(\text { dcap }_{j}\right)^{\mu^{1}}\right]^{1-\iota_{i j}^{M}}
$$

where $\iota_{i j}^{M}$ is an indicator for whether $i$ and $j$ belong to the same state, $\mu_{s s^{\prime}, t}$ is a symmetric interstate migration cost (i.e., $\mu_{s s^{\prime}, t}=\mu_{s^{\prime} s, t}$ ), and $d c a p_{i}$ is the travel distance between region $i$ and the state capital of $i$. As such, workers have to pass through the capital to access meso-regions in other states. ${ }^{39}$

To recover $\mu_{s s^{\prime}, t}$, based on our parameterization in equation (15), we use OLS to estimate the following equation:

$$
\log \left(L_{s s^{\prime}, k t}\right)=\alpha_{s, t}+\alpha_{s^{\prime}, k t}+\tilde{\mu}_{s s^{\prime}, t}+\epsilon_{s s^{\prime}, k t},
$$

where $\alpha_{s, t}$ and $\alpha_{s^{\prime}, k t}$ are destination-activity and origin fixed effects, $\tilde{\mu}_{s s^{\prime}, t} \equiv-\kappa \log \left(\mu_{s s^{\prime}, t}\right)$ and $\epsilon_{s s^{\prime}, k t}$ is an error term. ${ }^{40}$ Given our estimates of $\mu_{s s^{\prime}, t}$, we adjust $\mu_{t}^{0}$ in the model to match the share of workers living in their meso-region of birth and $\mu_{s s^{\prime}, k t}$ to match the migration of workers between states and activities. We set $\mu^{1}$ to 0.05 , which controls the elasticity of migration costs with respect to distance, based on Bryan and Morten (2019). ${ }^{41}$

\subsection{The March to the West as seen Through our Model}

Table 4 presents selected descriptive statistics of our calibration. Each panel highlights a different type of exogenous driver that can generate migration of workers across Brazilian regions in our model: migration costs, productivity, and trade costs.

Panel (a) shows that domestic migration costs declined sharply between 1950 and 1980, in line with what we expect, given Brazil's large-scale public investments in transportation infrastructure. ${ }^{42}$ Migration costs from the East to the West declined the most, a two-thirds

\footnotetext{
${ }^{39}$ This formulation, often referred to as hub-spoke, allows us to aggregate migration flows and run gravity equations in a theoretically consistent manner (see Appendix E). Although in our model and data an observation is a meso-region, note that we target state-state-activity flows in this calibration. The reason is these data have a higher level of aggregation, which makes it less likely that we wrongly infer infinite migration costs from sampling zeros.

${ }^{40}$ Appendix E shows how to derive expression (16) using (15). Our estimates of $\mu_{s s^{\prime}, t}$ are also strongly correlated with the Head and Ries index, which is a common measure of trade cost based on gravity models, but applied to aggregate migration flows between states $\left(L_{s s^{\prime}, t}=\sum_{k} L_{s s^{\prime}, k t}\right)$.

${ }^{41}$ Using our calibrated values for $\mu^{1}$, the reduced form elasticities generated by our model at the state level are comparable to the elasticities estimated in Morten and Oliveira (2016). We find an elasticity of state to state migration flow with respect to distance of -1.36, whereas Morten and Oliveira (2016) find a coefficient of -1.16 .

${ }^{42}$ To compute the measures of migration cost discussed in this section, we remove $\mu_{s s^{\prime}, k t}$ from $\mu_{i j, k t}$, since $\mu_{s s^{\prime}, k t}$ can be interpreted as sectoral wedges that are not related to geography. Results are qualitatively the
} 
reduction, but migration costs within the West and within the East also declined substantially. Figure 5 correlates our estimates of the symmetric component of migration cost $\left(\mu_{s s^{\prime}, t}\right)$, recovered from the fixed effects from equation (16), with distance between states. Reassuringly, migration costs are strongly correlated with distance, even though we do not use any measure of distance in our estimation of $\mu_{s s, t}$. Consistent with increased government investment to deepen ties between the East and the West, this correlation drops over time as shown in Panel (a). To benchmark our migration costs with previous literature, we note that our migration cost estimates are comparable with the ones obtained in Tombe and Zhu (2019), who find an overall migration cost between provinces in China of 25 circa 2000.

Panel (b) shows the evolution of productivities, $A_{i, k t}$, in the West relative to the East. The West's agricultural productivity caught up and surpassed that of the East - a reason for the mismatch between labor allocation and productivity that we discussed in Section 4.3. For soybeans, specifically, the upward trend in relative productivity is in line with the research efforts from EMBRAPA to increase soybean productivity in the West in the 1970s. Panel B also indicates that the productivity of the land supply sector, as measured by $b_{j, t}$, increased from 1950 to 2010 in the West relative to the East, which is consistent with the government's increasing efforts to facilitate land settlement and acquisition in the West.

Panel (c) shows that our calibration also captures Brazil's increasing trade openness through a reduction of international trade costs. Domestic trade costs also declined and became less sensitive to distance, in line with the transportation policies that fostered EastWest trade integration.

Put together, these results paint a clear picture of the forces that produced the March. Starting in the 1950 s, a series of shocks dramatically increased the West's agricultural productivity across the board, especially in new crops such as soybean and corn. In response to concomitant reductions in East-West migration costs, and taking advantage of these productivity shocks and of the West's relative abundance of land, Eastern migrants sorted throughout the West and fueled its expansion into domestic and foreign markets.

\section{The Quantitative Impact of Migration on Trade}

In this section, we evaluate the quantitative importance of migration as a driver of trade specialization. Motivated by the Brazilian government's domestic integration policies, we ask: What would have happened if these policies, as they pertain to migration costs, had never been enacted? We examine a counterfactual economy in which migration costs between the East and the West remain at their 1950 levels, while all other exogenous shocks evolve as

same if we incorporate $\mu_{s s^{\prime}, k t}$ into $\mu_{i j, k t}$. 
in the baseline economy. We then examine how worker heterogeneity and Heckscher-Ohlin forces shape these main results. The discussion that follows focuses on our cumulative results for 2010, but our partial results for 1980 are contained in Appendix Figure A.6.

In the data, the share of employment in the West rose from 6.9 percent in 1950 to 15 percent in 2010. In our counterfactual economy, it only rises to 10.6 percent. Under this metric, migration costs account for 56 percent of the migration to the West. This shows that migration costs are a powerful driver of the allocation of population over space, although other factors, including productivity, land supply, and trade costs shocks, also played a critical role.

\subsection{The Impact of Migration Costs on Specialization}

Figure 6 plots, on the vertical axis, counterfactual changes in specialization across regions in the West, relative to the rest of the world, using manufacturing as a reference (i.e., we use our RBE index). ${ }^{43}$ The horizontal axis shows, for each region and activity relative to manufacturing, the baseline share of workers born in the West in total effective labor supply of that region-activity. With Proposition 1 in mind, the smaller this baseline share, the more exposed is the region-activity pair to a reduction of immigration from the East, compared to manufacturing.

We highlight three patterns from this figure. First, most region-activity pairs fall below zero on the vertical axis, meaning that reductions in migration costs shifted trade towards agriculture and away from manufacturing. Second, although soybean production is the most affected activity with specialization shifting often by more than 50 percent, the impact is also large for other, more traditional activities. Third, there is a strong relation between exposure to migration and changes in specialization - suggesting that the intuitions from Proposition 1 carry over to this more general counterfactual. In sum, migration costs are a key driver of regional comparative advantage.

In Figure 7, we aggregate these regional changes for the West and for Brazil. Panel (a) confirms that the decline of migration costs led to a marked expansion of the West's agriculture relative to manufacturing. It also shows that the agricultural activities that are more exposed to East migrants in the West are the ones that expanded the most due to migration (recall Fact 2). Counterfactual specialization relative to the baseline is 58 percent lower for soy and about 35 percent lower for beef and corn. In addition, among the activities that benefited most from migration in the West are some traditional crops, such as coffee

\footnotetext{
${ }^{43}$ The exposures in the East to migrants from the West are much lower in general, as suggested by Figure 4. This means that the vast majority of our aggregate results follow from the regional changes we discuss in this section.
} 
and cacao. However, as Panel (b) shows, this had little impact on the specialization of Brazil as a whole. The reason is that, although these traditional crops grew in the West, the West's share in the aggregate production of these traditional crops is minimal. In contrast, aggregate counterfactual drops in soy and cattle specialization are large (29 and 25 percent) and follow, to a large extent, the evolution of the West's agriculture. ${ }^{44}$

Appendix Figure A.7 shows that internal migration, induced by changes in migration costs, also accounts for up to 30 percent of the country-wide observed evolution of specialization in soy, cattle, and corn between 1950 and 2010 (or 27 percent of the observed evolution of the export shares over the same period). For the West, migration accounts for almost twice as much.

In sum, through a large and heterogeneous reallocation of workers across activities and regions, migration cost reductions had a large impact on Brazil's production costs relative to the rest of the world and drove large changes in Brazilian agricultural specialization.

\subsection{Quantifying the Margins of Comparative Advantage}

We now turn to measure the contribution of factor intensity and worker heterogeneity to our results. To do so, we recalibrate the model under several specifications and compute the same counterfactual scenarios in which migration costs remain at their 1950 levels.

\subsubsection{Factor Proportions}

In our baseline calibration, agriculture is the only activity that uses land in production, so Heckscher-Ohlin forces operate only between manufacturing and agriculture. In Figure 8 we compare our baseline results to those in a model that recognizes that land intensity varies within agriculture between crops and cattle. Doing so mitigates the impact of migration on cattle specialization - almost 1.3 p.p. in the aggregate, or 5.3 percent lower. For most other agricultural activities, the impacts are also modestly smaller.

Underneath these aggregate counterfactual changes, East and West respond in opposite directions. In unreported results, we find for the West as a whole a 17 percent smaller counterfactual drop in cattle specialization, while for all other crops we observe modest increases. The reason is that, in this new calibration, land commands a larger value-added share in cattle, compared to other agricultural activities (0.33 vs 0.17). Hence the direct impact of a labor shortfall on marginal costs is lower for cattle than for crops. Because the land supply is not perfectly elastic, in equilibrium the price of land declines, which also

\footnotetext{
${ }^{44}$ Cotton responds strongly to migration costs shocks both in the West and in the aggregate. As Table 1 showed, however, it is relatively unimportant in the aggregate.
} 
favors land-intensive activities the most. For the East, we obtain opposite results because that region experiences a counterfactual labor-supply increase. The aggregates in Figure 8 average regional changes according to importance of each region in the exports of each crop.

\subsubsection{Worker Heterogeneity I: Impact on Specialization}

Proposition 1 suggests that migration operates through variation in effective-labor exposure across regions and activities. With the exception of sector-specific migration costs, $\mu_{s s^{\prime}, k t}$, in our model the only force generating sorting is origin-specific worker heterogeneity, $s_{i, k t}$. To assess the importance of worker heterogeneity for the impact of migration, we recalibrate our model in steps. First, we modify our base calibration to target origin-destination labor flows and, separately, employment by activity and region. ${ }^{45}$ This first step removes the sorting across activities that comes purely from $\mu_{s s^{\prime}, k t}$ (i.e., we replace $\mu_{s s^{\prime}, k t}$ with $\mu_{s s^{\prime}, t}$ and $\mu_{s^{\prime}, k t}$ ). In the second step, we recalibrate the model by additionally setting $\beta=0$, which shuts down sorting completely (yielding exposure $\mathcal{E}_{i i, k} / \mathcal{E}_{i i, l}=1$ for any $k$ and $l$ ).

Starting with the West, Figure 9 (a) plots, for each crop, the counterfactual aggregate change in specialization in our baseline calibration and compares it to those in these two new calibrations. Completely eliminating sorting dramatically affects specialization across the board. Among crops in which the baseline impact of migration is large, we observe largest effects on soybean specialization, which drops by about 42 percent relative to our baseline, but the effect is also sizable for cacao, coffee, and beef (40, 21, and 10 percent). Focusing again on soy, about one-third of the effect of sorting comes from worker heterogeneity, as opposed to migration costs. We conclude that knowledge, and sorting more generally, was critical in the differential expansion of agricultural activities in the West.

Turning to Brazil as a whole, the role of knowledge is most quantitatively important for soybean: absent sorting, the impact of migration on specialization would be about a 29 percent smaller and, again, about one-third of this reduction is due to knowledge. Repeating these exercises with $\beta=0.083$ (Appendix Figure (A.10)) essentially retains the total role of sorting unchanged, but increases the importance of knowledge heterogeneity, which moves from one third to one half.

\subsubsection{Worker Heterogeneity II: Steady state implications}

We now exploit the dynamic structure of our model to examine how, matching exactly the same data in 1950, 1980, and 2010, the paths of the economy would diverge in the long run

\footnotetext{
${ }^{45} \mathrm{An}$ indication of the importance of this mechanism is that, in our baseline calibration, a regression of effective labor flows across origins and destination-activity pairs, $L_{i j, k}$, against skill heterogeneity, $s_{i, k}$, accounts for 55 percent of the variation in 2010 and 32 percent in 1980.
} 
with different values of $\beta{ }^{46}$ We find that Brazil's agricultural transformation is far from complete. Export specialization in soybean continues to intensify, as do this crop's export and revenue shares; meanwhile all other crops - among them cattle and corn - become less important. Aggregate export and revenue shares of soybeans continue to grow and settle about 15 p.p. and 1 p.p. higher in the presence of worker heterogeneity, i.e., slightly more than double their 2010 levels.

The endogenous adjustment of knowledge, $s_{i, k}$, underlies these results: On the one hand, migration makes worker knowledge available to all regions; on the other hand, in the presence of migration costs, knowledge rises disproportionately in high-employment regions, because workers are more likely to stay there. As Figure 10 shows, these forces play out most prominently in the case of soy, for which the elasticity of international specialization to relative productivity increases by 0.32 percentage points ( 8 percent). This outcome is explained by the fact that soy is a large-employment activity and, moreover, this employment is concentrated in a few regions. Thus, the reallocation of knowledge quantitatively reinforces natural advantage differences. ${ }^{47}$

\section{Migration, Comparative Advantage, and the Gains from Trade}

To complete our evaluation of the impact of migration on international trade, we assess how it affects the gains from trade (hereafter, GFT). In our model, a natural way to study counterfactual changes in welfare is to focus on the expected utility attained by a person born in region $i, \Xi_{i}{ }^{48}$ We proceed in four steps. First, we show that, with only one activity, there is an ex-ante sufficient statistic to compute each region's "full" GFT, i.e., the losses from shutting down trade with every other region. Second, we highlight that migration produces two new channels for these GFT: one related to the effects of migration on regional terms of trade and another related to the changing value of migration opportunities. Third, we show

\footnotetext{
${ }^{46}$ To obtain the steady state, we simulate the economy forward, keeping all exogenous productivity, trade, migration, and land wedges constant at their 2010 levels, until period to period changes in wages and employment are negligible. Although dynamics are long-lived, the largest part of the steady-state transformation occurs rapidly: the half-life of the the differential between the $\beta=0.04$ and $\beta=0$ calibrations is only 2 periods.

${ }^{47}$ Appendix Figure A.9 collects all our results for changes in specialization at the regional and aggregate levels, both in 2010 and the steady state, for a specification that removes the scale effects of knowledge, that is, $s_{i, k}=\bar{s}\left(L_{i, k t-1} / L_{i, A t-1}\right)^{\beta}$ and shows that this choice makes little quantitative difference.

${ }^{48}$ Using this metric, we compute GFT as the welfare costs of autarky or $1-\hat{\Xi}_{i}$, where $\hat{\Xi}_{i}$ is the proportional change in welfare from going to autarky (see Costinot and Rodríguez-Clare, 2015). The results in this section complement the approach in Galle, Rodríguez-Clare, and Yi (2017) in which workers sort based on productivity heterogeneity and geographic mobility frictions do not play a prominent role.
} 
quantitatively that migration and comparative advantage are key drivers of the full GFT across regions. Lastly, exploiting the results built in the previous steps, we investigate how the March to the West influenced Brazil's gains from trading internationally, which we will refer to as the "international" GFT. To obtain the analytical results presented in this section, we return to our simplified model in which land is not a productive factor. We focus again on 2010, but Appendix Figure A.8 shows that our conclusions hold also for 1980.

\subsection{Gains from Trade with One Activity}

We start with a result that, following directly from the definitions of $\Xi_{i}$ and of trade shares $\pi_{i i}$, highlights that changes in expected utility depend on changes in real wages in all regions to which workers can migrate; these changes, in turn, can be computed using observed regional trade shares.

Proposition 2. Using observed trade shares, one can compute the losses from full trade autarky, i.e. $\tau_{i j} \rightarrow \infty, \forall i \neq j$, as

$$
\hat{\Xi}_{i}^{B \rightarrow B, A}=\left(\sum_{j} \lambda_{i j} \pi_{i i}^{\frac{\kappa}{\alpha(\eta-1)}}\right)^{1 / \kappa},
$$

where $\lambda_{i j}$ are observed migration shares and $\pi_{i i}$ are observed domestic expenditure shares, and where " $B$ " denotes baseline and " $B, A$ " denotes trade autarky starting from $B$.

Absent migration, i.e. when $\lambda_{i i}=1$ and $\lambda_{i j}=0$ for any $j \neq i$, equation (17) collapses to the canonical formula for the GFT (see Arkolakis, Costinot, and Rodriguez-Clare, 2012). The next proposition relates the GFT starting in our baseline to those in a situation where migration across regions is not allowed. ${ }^{49}$

Proposition 3. For region $i$, the autarky losses in the baseline economy $\hat{\Xi}_{i}^{B \rightarrow B, A}$ and the no-migration economy $\hat{\Xi}_{i}^{N \rightarrow N, A}$ are related by the following equation

$$
\hat{\Xi}_{i}^{B \rightarrow B, A}=[\underbrace{\lambda_{i i} T_{i}^{-\kappa}\left(\hat{\Xi}_{i}^{N \rightarrow N, A}\right)^{\kappa}}_{\text {domestic contribution }}+\underbrace{\sum_{j \neq i} \lambda_{i j}\left(\pi_{j j}^{B}\right)^{\frac{\kappa}{\alpha(\eta-1)}}}_{\text {migration opportunities contribution }}]^{1 / \kappa},
$$

where $T_{i}=\left(\pi_{i i}^{B} / \pi_{i i}^{N}\right)^{1 / \alpha(1-\sigma)}$.

\footnotetext{
${ }^{49}$ Bonadio (2020) studies the direct impact of international migration on welfare, highlighting how it impacts market access for receiving regions.
} 
The first thing to note is that two components contribute to the baseline losses from full autarky. ${ }^{50}$ The first component is the losses from autarky that would occur without migration, $\hat{\Xi}_{i}$, whose weight is given by the fraction of workers who stay in $i, \lambda_{i i}$. The coefficient $T_{i}$ corrects for the fact that migration, by itself, worsens the terms of trade for regions that receive workers. The second component measures the contribution of migration opportunities: Additional welfare losses also arise from migration destinations in which real wages drop when there is no trade. Note that if region $i$ is a large receiver of migrants and hence $T_{i}$ is small — the losses from autarky tend to be smaller in the baseline economy than in the economy without migration, and so migration attenuates the losses from autarky (i.e., migration reduces the gains from trade).

\subsection{Gains from Trade with Multiple Activities}

We now return to our baseline simulation to study the welfare cost of autarky quantitatively. We emphasize that the forces we have uncovered in Section 7.1-which state how migration opportunities shape the full GFT with one activity - carry over to a model with multiple activities. Namely, (i) changes in real wages in other regions contribute to the GFT, and (ii) migration by itself induces changes in local real wages via changes in the terms of trade. ${ }^{51}$

With multiple activities, these migration-related forces interact with comparative advantage. For one thing, larger proportions of workers sort into region-activity combinations with high efficiency relative to the rest of the world, governing the initial $\lambda_{i j, k}$ shares. For another, comparative advantage activities tend to experience larger reductions in real wages from going to trade autarky.

Figure 11 (a) presents the full GFT. The gains are large, (on average 26 percent), but also vary substantially across regions. Using equation (18), we can compute the share of the full GFT accounted for exclusively by migration opportunities (i.e., the welfare loss from real wage losses in migration destinations). ${ }^{52}$ Figure 11 (b) plots this share against the fraction of

\footnotetext{
${ }^{50}$ We continue to write changes in real wages as a function of domestic trade shares $\pi_{i i}$ although the first term is not directly observable, to both keep the symmetry with equation (17) and emphasize that some of these components are directly observable.

${ }^{51}$ Dix-Carneiro and Kovak (2017) have shown that exposure to a trade liberalization shock has protracted, negative effects across Brazilian labor markets. Our results in this section show that negative outcomes in a local labor market also impact welfare for workers who could potentially migrate to that labor market.

${ }^{52}$ That is, we set $T_{i}^{-\kappa}\left(\hat{\Xi}_{i}^{N \rightarrow N, A}\right)^{\kappa}$ equal to 1 in Equation (18) and divide by the full GFT. Appendix D shows the equivalent of expression (18) in a model with many activities, which we use to make these calculations. Although a decomposition such as (18) — which exactly links welfare losses in the two scenarios - is not available in a model with multiple activities, one can still easily separate the contribution of migration opportunities to the total gains from trade, as we do in this exercise. The correction term $T$ adds little quantitatively to our results. The average $T_{i}^{-\kappa}$ across meso-regions is approximately 1.01 with a standard deviation of 0.06 .
} 
people leaving each region. The contribution of migration opportunities ranges from minimal to, for a large number of regions, almost the full losses from trade, with an average of 61 percent. The migration-opportunity contribution is correlated with the fraction of people who leave when migration is available, $1-\sum_{k} \lambda_{i i, k}$, as one expects from Equation (18). But the correlation is far from perfect, which highlights that comparative advantage and regional heterogeneity are also key determinants of the importance of migration opportunities. Since the West tends to receive workers from the East, the migration-opportunity contribution is smaller on average for the former than the latter (49 percent and 62 percent; see Panel (c)). This share is particularly low in large urban centers in the East and expanding agricultural regions in the West.

To assess the direct impact of comparative advantage on the full GFT, we compute the ratio of the GFT in a model with one activity relative to a model with multiple ones. ${ }^{53}$ As panels (d) and (e) show, the contribution of multiplicity of activities to the GFT is strongly associated with comparative advantage in agriculture relative to the rest of the world (measured as autarky relative price indexes). For many regions in the West, in particular, including heterogeneity across activities almost doubles the GFT. Since it is inherently a local characteristic, comparative advantage operates chiefly by strengthening the response of local real wages to trade (i.e., the domestic component in equation (18)), and less so by shifting migration opportunities (the second component in equation (18)).

Lastly, we study in Panel (f) how migration and comparative advantage interact to determine the GFT. On the y-axis, we measure how the contribution of migration opportunities changes, when going from a one-activity model to one with multiple activities. On the x-axis we measure again the GFT with many activities relative to the GFT with one activity. The figure shows a clear negative relation, with a slope of -0.51 , which means that the larger the role of comparative advantage in the GFT, the smaller the share of migration opportunities in the GFT (relative to a one activity model). Hence, although migration opportunities create further gains from trade in a many-activity model (relative to a one activity one), these further gains do not rise as fast as the additional gains coming from domestic markets.

\subsection{The Impact of East to West Migration on the International GFT}

Having established the contribution of different economic mechanisms in the case of full GFT and full migration autarky, we now return to our main counterfactual and study the international GFT. We concentrate on the core mechanisms and provide additional discussion in Appendix F.

\footnotetext{
${ }^{53}$ We calculate the one-sector losses using equation (17). Levchenko and Zhang (2016) perform a similar comparison underscoring the quantitative importance of comparative advantage.
} 
Figure 12 (a) maps the international GFT across regions. For Brazil as a whole, the international GFT are 5.0 percent, reflecting that it is a relatively closed economy. Within the country, nevertheless, there are regions for which international trade is crucial, and limiting it can cut down welfare by as much as 11 percent. Panel (b) presents the impact of limiting East-West migration on the gains from international trade. The average international GFT drops by a modest 3.1 percent ( 0.15 percentage points out of the 4.9 percent baseline), but again, across regions, the differentials range from -19 to 7 percent. The impact of migration is particularly large for the Central-West region, which hosts a large production share of Brazil's new export activities, and which also received the majority of Eastern migrants. We now proceed to disentangle the forces behind these international GFT differentials.

Echoing our previous results, we begin by computing the contribution of East-West migration to international GFT in our baseline economy. Across regions, on average 22 percent of the international GFT are associated with East-West migration opportunities. In the counterfactual economy, these opportunities are not available to workers, which tends to lower the international GFT across the board.

To understand the regional variation in Panel (b), the interaction between migration and comparative advantage is key. Consider first what happens to real wages in each region. From Fact 2, we know that Eastern workers sort disproportionately into agriculture when they migrate to the West and, especially, the Central-West. This means that Eastern migrants sort according to the West's international comparative advantage, which makes Western sales more reliant on international markets, rather than domestic ones. In the West, therefore, the drop in real wages from going to international trade autarky is larger in the baseline, when migration is allowed. The exact opposite happens (i) in a few regions in the northeast - which also have a comparative advantage in agriculture relative to ROW, but instead receive the Eastern agricultural workers in the no-migration counterfactual - and (ii) in the manufacturing regions in the Amazon, such as Manaus. In the rest of the East, because changes in labor supply are small, these effects are quite muted. Finally, note that an additional consequence of limiting migration is to make local real wages, relative to the ones associated with migration opportunities, have a larger weight in the expected welfare of workers born in each region.

Putting these forces together, we conclude that the international GFT in high-employment regions in the East were not greatly affected by migration, which explains why aggregate GFT are insensitive to it. But the large heterogeneity we observe across other regions is driven by how migration interacts with the forces of comparative advantage. 


\section{Conclusions}

Labor allocation within a country shapes regional and aggregate comparative advantage. In the Brazilian experience, the decline in East-West migration costs started in 1950 was an important driver of the March to the West and, as we showed in this paper, encouraged the development of new industries, such as soy, cattle, and corn, ultimately helping to transform Brazil's agriculture. Key to these new developments was that workers from the East, where these commodities were already being produced, took advantage of rapid productivity growth in new sectors in the West through migration.

Previous research - including ours - often takes comparative advantage as an unchanging feature of the world. This paper shows that comparative advantage evolves to reflect the way migration interacts with, and sometimes amplifies, natural advantage. We have also shown how policies to improve spatial labor mobility complement other policies whose impact is localized, such as boosting regional productivity, or country-wide, such as tariffs, to determine their ultimate impact.

\section{References}

ADÃO, R. (2015): "Worker heterogeneity, wage inequality, and international trade: Theory and evidence from brazil," Unpublished paper, MIT.

Allen, T., and C. Arkolakis (2014): "Trade and the Topography of the Spatial Economy," The Quarterly Journal of Economics, 129(3), 1085-1140.

Allen, T., And D. Atkin (2016): "Volatility and the Gains from Trade," Working Paper 22276, National Bureau of Economic Research.

Allen, T., And D. Donaldson (2020): "Persistence and Path Dependence in the Spatial Economy," .

Alvarez, F., And R. J. LuCAs (2007): "General equilibrium analysis of the Eaton-Kortum model of international trade," Journal of Monetary Economics, 54(6), 1726-1768.

Amann, E., C. Azzoni, and W. Baer (2018): The Oxford handbook of the Brazilian economy. Oxford University Press.

Antweiler, W., And D. Trefler (2002): "Increasing Returns and All That: A View from Trade," American Economic Review, 92(1), 93-119. 
Arkolakis, C., A. Costinot, and A. Rodriguez-Clare (2012): "New Trade Models, Same Old Gains?," American Economic Review, 102(1), 94-130.

Arkolakis, C., S. K. Lee, and M. Peters (2018): "European Immigrants and the United States' Rise to theTechnological Frontier in the 19th Century," .

Artuç, E., S. Chaudhuri, and J. Mclaren (2010): "Trade Shocks and Labor Adjustment: A Structural Empirical Approach," American Economic Review, 100(3), 1008-45.

Baer, W. (2001): Brazilian Economy, The: Growth and Development: Growth and Development. ABC-CLIO.

Bahar, D., and H. RApoport (2016): "Migration, knowledge diffusion and the comparative advantage of nations," The Economic Journal.

BALASSA, B. (1965): "Trade liberalisation and revealed comparative advantage 1," The manchester school, 33(2), 99-123.

Bartelme, D. G., A. Costinot, D. Donaldson, and A. Rodríguez-Clare (2019): "The textbook case for industrial policy: Theory meets data," Discussion paper, National Bureau of Economic Research.

Bazzi, S., A. Gaduh, A. D. Rothenberg, and M. Wong (2016): "Skill Transferability, Migration, and Development: Evidence from Population Resettlement in Indonesia," American Economic Review, 106(9), 2658-2698.

Becker, S. O., I. Grosfeld, P. Grosjean, N. Voigtlander, and E. Zhuravskaya (2020): "Forced migration and human capital: evidence from post-WWII population transfers," American Economic Review, 110(5), 1430-63.

Bird, J., And S. Straub (2020): "The Brasília experiment: The heterogeneous impact of road access on spatial development in Brazil," World Development, 127, 104739.

Bombardini, M., G. Gallipoli, and G. Pupato (2012): "Skill Dispersion and Trade Flows," American Economic Review, 102(5), 2327-2348.

Bonadio, B. (2020): "Migrants, Trade and Market Access," .

Browder, J. O., M. A. Pedlowski, R. Walker, R. H. Wynne, P. M. Summers, A. Abad, N. Becerra-Cordoba, and J. Mil-Homens (2008): "Revisiting theories of frontier expansion in the Brazilian Amazon: a survey of the colonist farming population in Rondonia's post-frontier, 1992-2002," World Development, 36(8), 1469-1492. 
Bryan, G., And M. Morten (2019): "The aggregate productivity effects of internal migration: Evidence from indonesia," Journal of Political Economy, 127(5), 2229-2268.

Buera, F. J., And E. Oberfield (2016): "The Global Diffusion of Ideas," Working Paper 21844, National Bureau of Economic Research.

Burchardi, K. B., T. Chaney, and T. A. Hassan (2019): "Migrants, Ancestors, and Foreign Investments," Review of Economic Studies, 86(4), 1448-1486.

Bustos, P., B. Caprettini, and J. Ponticelli (2016): "Agricultural productivity and structural transformation: Evidence from Brazil," American Economic Review, 106(6), 1320-65.

Bustos, P., J. M. Castro Vincenzi, J. Monras, and J. Ponticelli (2020): "Industrialization without Innovation," .

Cai, J., N. Li, and A. M. Santacreu (2019): "Knowledge Diffusion, Trade, and Innovation across Countries and Sectors," .

Caliendo, L., M. Dvorkin, and F. Parro (2019): "Trade and Labor Market Dynamics: General Equilibrium Analysis of the China Trade Shock," Econometrica, 87(3), 741-835.

Caliendo, L., and F. Parro (2015): "Estimates of the Trade and Welfare Effects of NAFTA," Review of Economic Studies, 82(1), 1-44.

Cardoso, M., and A. Ramanarayanan (2019): "Immigrants and Exports: Firm-level Evidence from Canada," .

Chor, D. (2010): "Unpacking sources of comparative advantage: A quantitative approach," Journal of International Economics, 82(2), 152-167.

Comin, D. A., D. LAshkari, And M. Mestieri (2015): "Structural change with long-run income and price effects," Discussion paper, National Bureau of Economic Research.

Cosar, A. K., and P. D. Fajgelbaum (2016): "Internal Geography, International Trade, and Regional Specialization," American Economic Journal: Microeconomics, 8(1), 24-56.

Costinot, A., And D. Donaldson (2014): "How Large are the Gains from Economic Integration? Theory and Evidence from U.S. Agriculture, 1880-1997," .

Costinot, A., D. Donaldson, and I. Komunjer (2012): "What Goods Do Countries Trade? A Quantitative Exploration of Ricardo's Ideas," Review of Economic Studies, $79(2), 581-608$. 
Costinot, A., D. Donaldson, and C. Smith (2016): "Evolving Comparative Advantage and the Impact of Climate Change in Agricultural Markets: Evidence from 1.7 Million Fields around the World," Journal of Political Economy, 124, 205-248.

Costinot, A., And A. Rodríguez-Clare (2015): "Chapter 4 - Trade Theory with Numbers: Quantifying the Consequences of Globalization," in Handbook of International Economics, ed. by K. R. Elhanan Helpman, and G. Gopinath, vol. 4 of Handbook of International Economics, pp. 197 - 261. Elsevier.

Courant, P. N., and A. V. Deardorff (1992): "International Trade with Lumpy Countries," Journal of Political Economy, 100(1), 198-210.

Crosby, A. W. (1973): The Columbian Exchange. Biological and Cultural Consequences of 1492, no. 2 in Contributions in American Studies. Greenwood.

DE LA Roca, J., And D. Puga (2017): "Learning by working in big cities," The Review of Economic Studies, 84(1), 106-142.

Deardorff, A. V. (2005): "How Robust is Comparative Advantage?," Review of International Economics, 13(5), 1004-1016.

Dias Avila, A. F., And R. E. Evenson (2010): Total Factor Productivity Growth in Agriculture: The Role of Technological Capitalvol. 4 of Handbook of Agricultural Economics, chap. 72, pp. 3769-3822. Elsevier.

Dix-Carneiro, R., and B. K. Kovak (2017): "Trade Liberalization and Regional Dynamics," American Economic Review, 107(10), 2908-46.

Eaton, J., And S. Kortum (2002): "Technology, Geography, and Trade," Econometrica, 70(5), 1741-1779.

- (2012): "Putting Ricardo to Work," Journal of Economic Perspectives, 26(2), 65-90.

Fajgelbaum, P., and S. Redding (2014): "External Integration and Internal Development: Evidence from Argentina, 1870-1914," NBER Working Papers 20217, National Bureau of Economic Research, Inc.

Farrokhi, F., And H. S. Pellegrina (2020): "Global Trade and Margins of Productivity in Agriculture," Working Paper.

French, S. (2017): "Revealed comparative advantage: What is it good for?" Journal of International Economics, 106(C), 83-103. 
Fujiwara, T., E. Morales, and C. Porcher (2020): "A Revealed-Preference Approach to Measuring Information Frictions in Migration," .

Galle, S., A. Rodríguez-Clare, and M. Yi (2017): "Slicing the Pie: Quantifying the Aggregate and Distributional Effects of Trade," Working Paper 23737, National Bureau of Economic Research.

Gouel, C., And D. Laborde (2018): "The Crucial Role of International Trade in Adaptation to Climate Change," Working Paper 25221, National Bureau of Economic Research.

Grossman, G. M., and G. Maggi (2000): "Diversity and Trade," American Economic Review, 90(5), 1255-1275.

Haberler, G. (1930): "Die Theorie der komparativen Kosten und ihre Auswertung für die Begründung des Freihandels," Weltwirtschaftliches Archiv, pp. 349-370.

Hanson, G. H., N. Lind, And M.-A. Muendler (2015): "The Dynamics of Comparative Advantage," Working Paper 21753, National Bureau of Economic Research.

IIASA/FAO (2012): Global Agro-ecological Zones (GAEZ v3.0). IIASA, Laxenburg, Austria and FAO, Rome, Italy.

Ireland, C. T., AND S. Kullback (1968): "Contingency tables with given marginals," Biometrika, 55(1), 179-188.

Kucheryavyy, K., G. Lyn, and A. Rodríguez-Clare (2016):.

Levchenko, A. A. (2007): "Institutional Quality and International Trade," Review of Economic Studies, 74(3), 791-819.

Levchenko, A. A., And J. Zhang (2016): "The evolution of comparative advantage: Measurement and welfare implications," Journal of Monetary Economics, 78(C), 96-111.

Lind, N., And N. Ramondo (2018): "Innovation, Knowledge Diffusion, and Globalization," Working Paper 25071, National Bureau of Economic Research.

Manova, K. (2013): "Credit Constraints, Heterogeneous Firms, and International Trade," Review of Economic Studies, 80(2), 711-744.

Marcolan, A. L., and M. C. Espindula (2015): Café na Amazônia. Brasília, DF: Embrapa, 2015. 
Morrow, P. M. (2010): "Ricardian-Heckscher-Ohlin comparative advantage: Theory and evidence," Journal of International Economics, 82(2), 137-151.

Morten, M., and J. Oliveira (2016): "The Effects of Roads on Trade and Migration: Evidence from a Planned Capital City," NBER Working Paper, 22158.

Nehring, R. (2016): "Yield of dreams: Marching west and the politics of scientific knowledge in the Brazilian Agricultural Research Corporation (Embrapa)," Geoforum, 77, 206217.

Nunn, N. (2007): "Relationship-Specificity, Incomplete Contracts, and the Pattern of Trade," The Quarterly Journal of Economics, 122(2), 569-600.

Ohnsorge, F., and D. Trefler (2007): "Sorting It Out: International Trade with Heterogeneous Workers," Journal of Political Economy, 115(5), 868-892.

Olmstead, A. L., And P. W. Rhode (2008): "Creating Abundance," Cambridge Books.

Olmstead, A. L., and P. W. Rhode (2011): "Adapting North American wheat production to climatic challenges, 1839-2009," Proceedings of the National Academy of Sciences, 108(2), 480-485.

Pellegrina, H. S. (2020): "Trade, Productivity, and the Spatial Organization of Agriculture: Evidence from Brazil," Working paper.

Porcher, C. (2020): "Migration with Costly Information," .

Porteous, O. (2019): "High Trade Costs and Their Consequences: An Estimated Dynamic Model of African Agricultural Storage and Trade," American Economic Journal: Applied Economics, 11(4), 327-66.

— (2020): "Trade and agricultural technology adoption: Evidence from Africa," Journal of Development Economics.

Ramondo, N., A. Rodríguez-Clare, and M. Saborío-Rodríguez (2016): "Trade, domestic frictions, and scale effects," American Economic Review, 106(10), 3159-84.

REDDING, S. J. (2016): "Goods trade, factor mobility and welfare," Journal of International Economics, 101(C), 148-167.

Redding, S. J., and E. Rossi-Hansberg (2017): "Quantitative Spatial Economics," Annual Review of Economics, 9(1), 21-58. 
Restuccia, D., D. T. YAng, and X. Zhu (2008): "Agriculture and aggregate productivity: A quantitative cross-country analysis," Journal of Monetary Economics, 55(2), $234-250$.

Sabel, C., E. Fernandez-Arias, R. Hausmann, A. Rodriguez-Clare, and E. Stein (2012): Export Pioneers in Latin America.

SCoville, W. C. (1951): "Minority migrations and the diffusion of technology," The Journal of Economic History, 11(4), 347-360.

Silva, J. S., and S. Tenreyro (2006): "The log of gravity," The Review of Economics and statistics, 88(4), 641-658.

Sotelo, S. (2020): "Domestic Trade Frictions and Agriculture," Forthcoming Journal of Political Economy.

Sviatschi, M. M., ET AL. (2018): "Making a narco: Childhood exposure to illegal labor markets and criminal life paths," Manuscript, Department of Economics, Princeton University. https://rpds. princeton. edu/sites/rpds/files/sviatschi making-a-narco march2018. $p d f$.

Tombe, T. (2015): "The Missing Food Problem," American Economic Journal: Macroeconomics, 7(3), 1-33.

Tombe, T., And X. Zhu (2019): "Trade, migration, and productivity: A quantitative analysis of china," American Economic Review, 109(5), 1843-72.

Vargas, G. (1938): A nova politica do Brasil - Vol V.

Vasconcelos, J. R. D. (2001): "Matriz do fluxo de comércio interestadual de bens e serviços no Brasil-1999," Discussion paper.

Villas BôAs, O., and C. Villas BôAs (1994): "A marcha para o oeste," A epopéia da Expedição Roncador-Xingu. São Paulo: Editora Globo.

Watson, A. M. (1983): "Agricultural innovation in the early Islamic world; the diffusion of crops and farming techniques, 700-1100," .

World Bank (1981): Brazil: Northwest Region Development Program: First Phase, Agricultural Development and Environmental Protection Project: Staff Appraisal Report. World Bank. 


\section{$9 \quad$ Figures and Tables}

Figure 1: The Share of Population, Agricultural Land Use, and Agricultural Value Added in Brazil's West

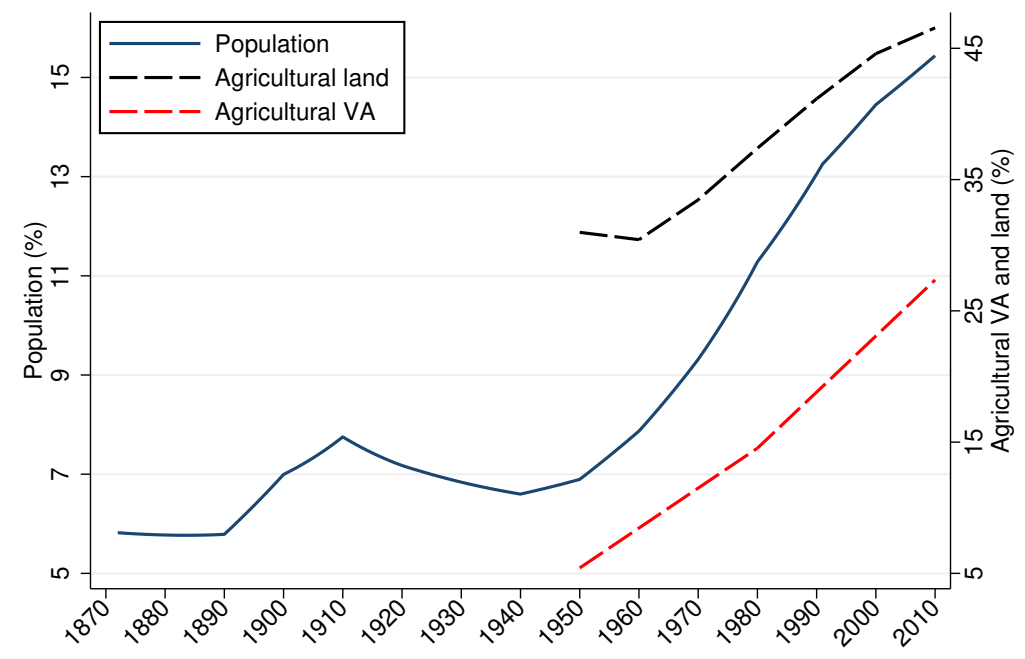

Notes: This figure shows the evolution of the the share of population, agricultural land, and agricultural value added in the West. The "March to the West" was first announced in 1937, but changes are only noticeable after 1950, following a series of economic and policy shocks.

Figure 2: The Spatial Distribution of the Brazilian Population between 1950 and 2010

(a) 1950

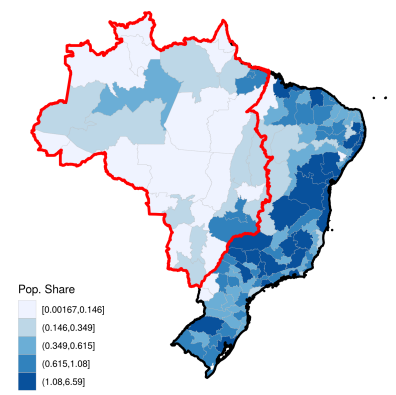

(b) 1980

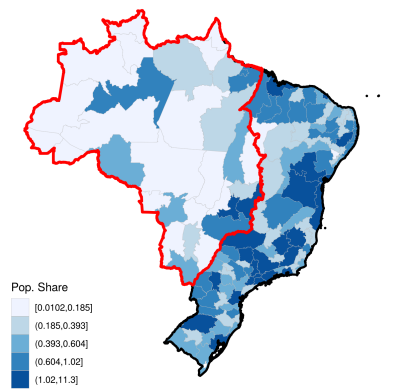

(c) 2010

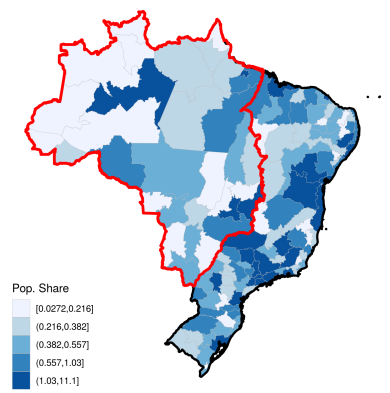

Notes: The figure shows the division of Brazil into meso-regions, which is the geographic unit used in our analysis. The red contour shows the meso-regions we classify as the West. The West incorporates the North and the Central-West, two of the five official regions defined by the Brazilian statistical bureu (IBGE). 
Figure 3: The Share of Workers in the West who were born there, by Economic Activity

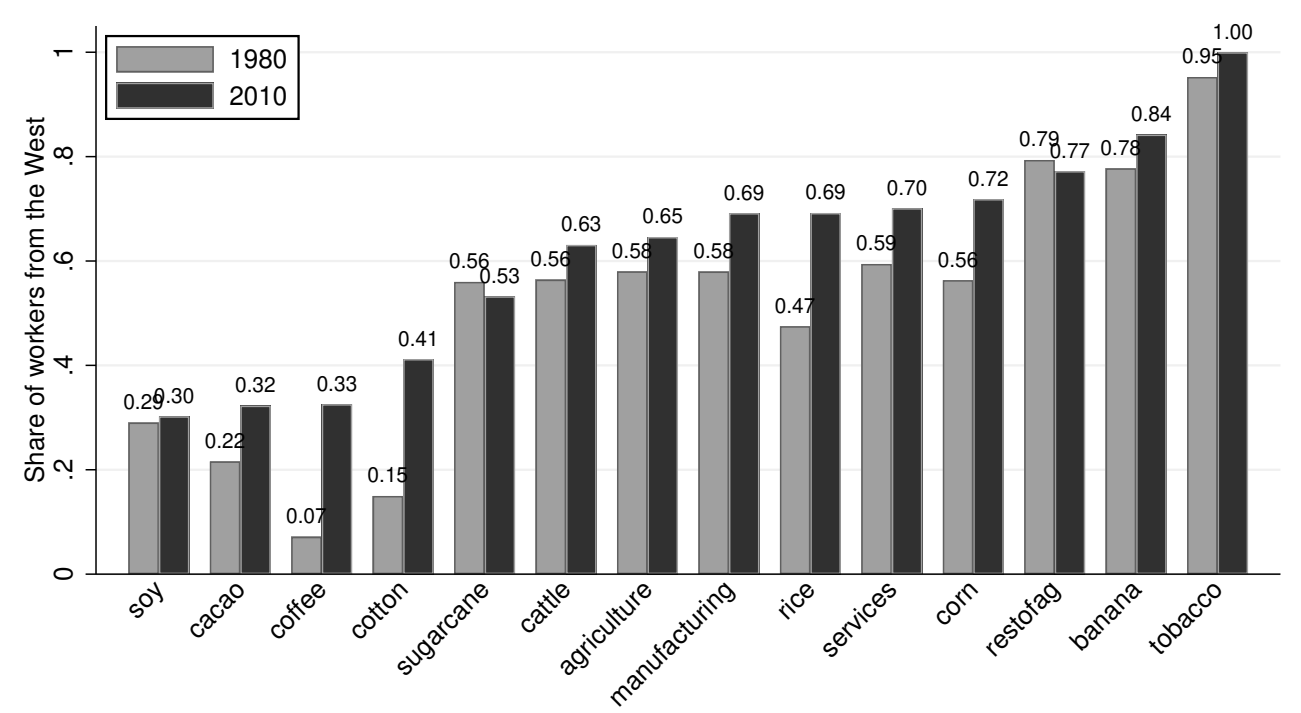

Notes: The figure presents the fraction of the total employment in the West, in each year, comprised by workers born in the West.

Figure 4: The Share of Workers born in the West across all States in 2010, for Selected Activities

(a) soy

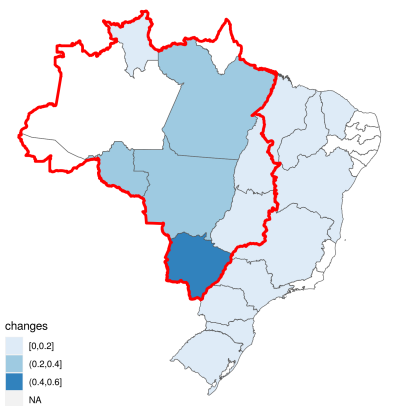

(b) cattle

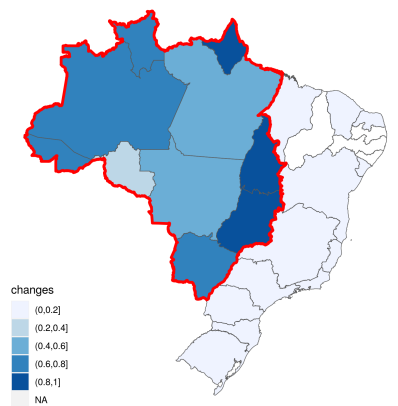

(c) corn

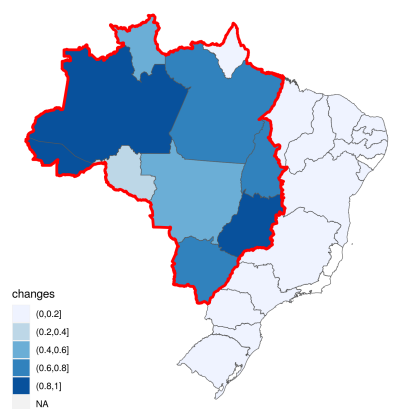

Notes: Each region is a state. For each state we present the fraction of the total employment in 2010 comprised by workers born in the West. The red contour shows the states we classify as the West. 
Figure 5: Correlation between Migration Costs and Distances

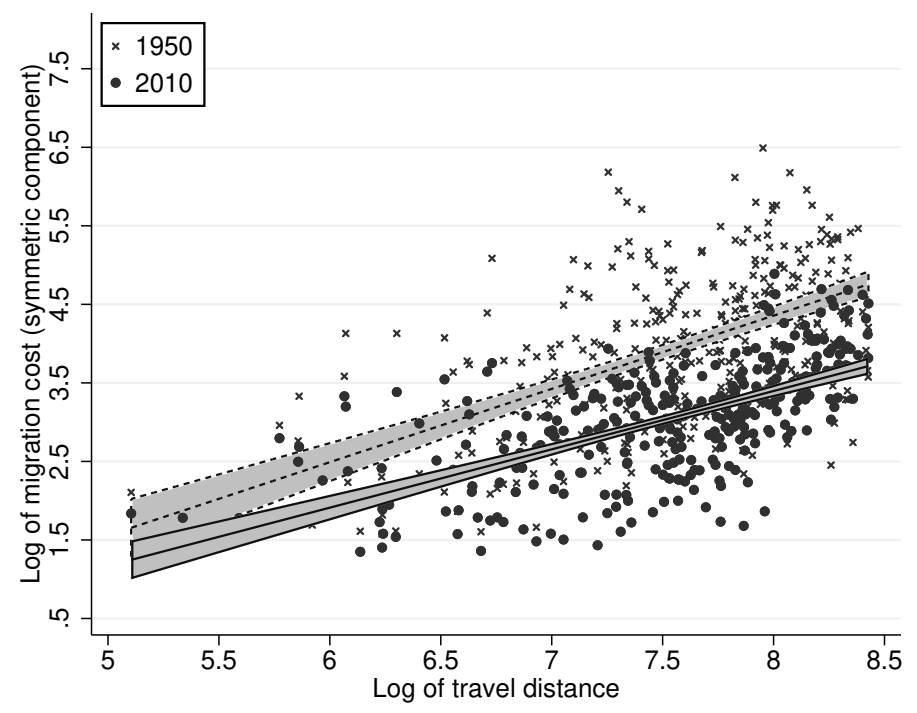

Notes: This figure plots the log of the symmetric component of migration costs between states $\left(\mu_{s s^{\prime}, t}\right)$ against travel distance between states. We estimate migration costs based on the fixed effects of gravity equations of migration in which we use no information on distance. Lines in the figure show the best linear fit and the 95 percent confidence interval.

Figure 6: Regional Exposure to Migrants and Changes in Export relative to Manufacturing (2010), across regions in the West

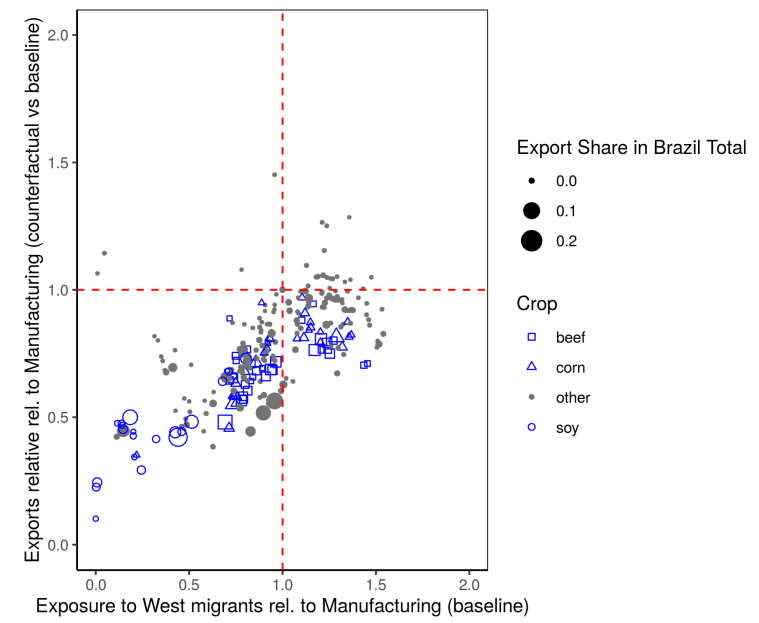

Notes: Each observation is a region-activity pair in the West. The horizontal axis measures the fraction of effective employment comprised by workers born in the West itself. The vertical axis shows the counterfactual change in exports relative to manufacturing (as a percentage of the baseline exports). The size of the markers represents the magnitude of exports in the baseline as a fraction of Brazil's total in that activity. 
Figure 7: Counterfactual Change in Exports relative to Manufacturing (2010), for the West and Brazil as a whole

(a) West

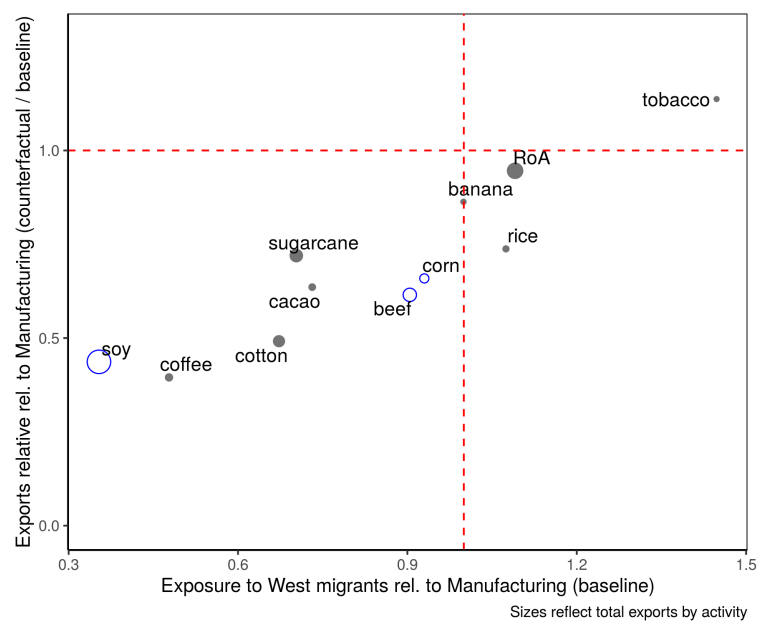

(b) Brazil

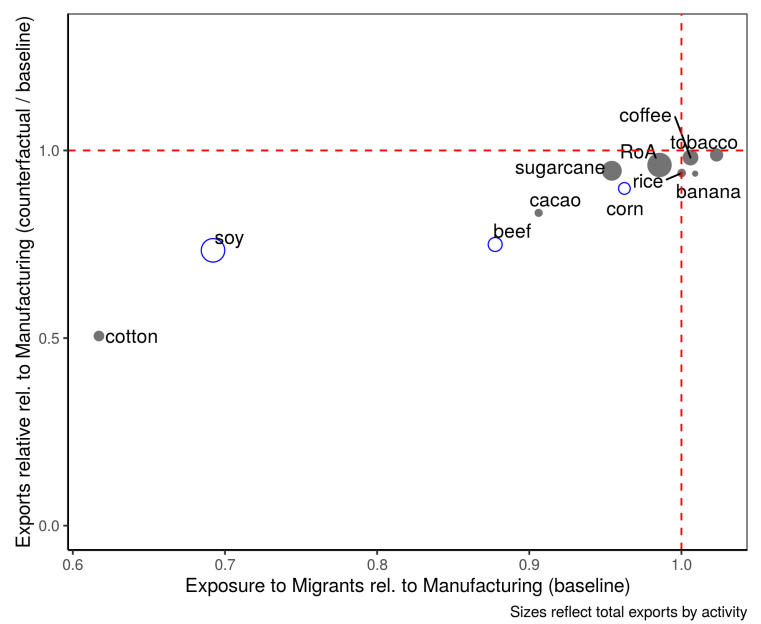

Notes: Panel (a): Each observation is an activity aggregate. The horizontal axis measures the fraction of effective employment in the West comprised by workers born in the West. The vertical axis measures the counterfactual change in West's exports relative to manufacturing (as a percentage the baseline value). The size of the markers represents the magnitude of exports in the baseline. Panel (b): Each observation is an activity aggregate. The horizontal axis measures the fraction of effective employment born in the same region where they work, weighted by baseline exports. The vertical axis shows the counterfactual change in Brazil's exports relative to manufacturing (as a percentage of the baseline value). The size of the markers represents the magnitude of exports in the baseline. 
Figure 8: Measuring the Contribution of Factor Intensity (2010)

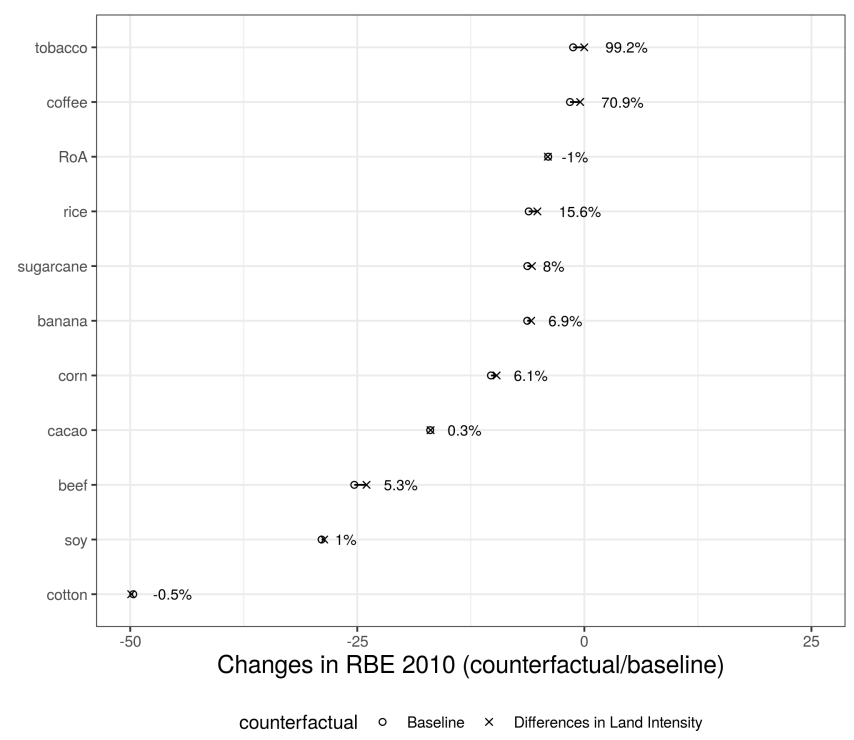

Notes. Each row is an activity aggregate at the country level. The hollow circle presents the counterfactual change in export specialization in our baseline calibration. The cross presents the counterfactual change in specialization in a calibration that gives different land intensities in production to crops and cattle. The numbers represent the drop in the second counterfactual relative to the baseline, in percentage terms. 
Figure 9: Measuring the Contribution of Knowledge (2010)

(a) In the West

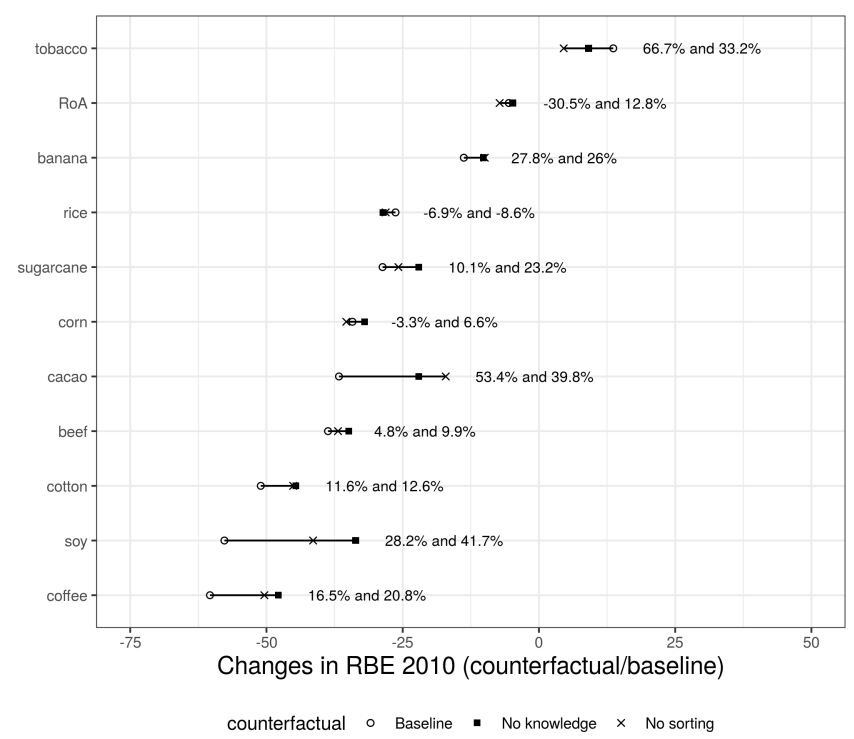

(b) In Brazil

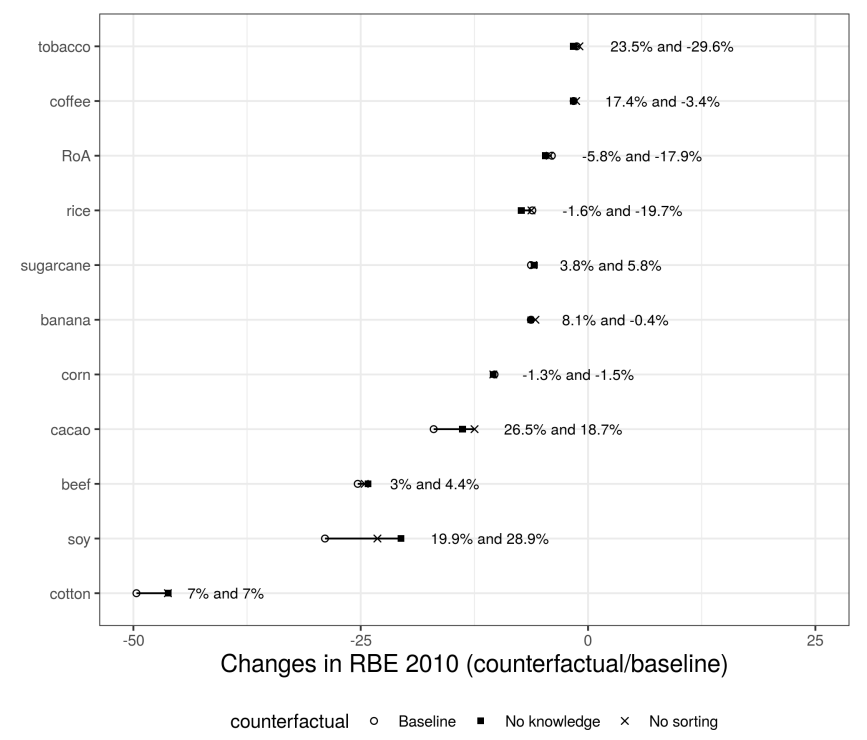

Notes. Each row is an activity aggregate. The hollow circle presents the counterfactual change in export specialization in our baseline calibration, which targets state-state-employment flows. The cross presents the counterfactual change in specialization in a calibration that targets state-state migration and state-activty employment, separately. The square corresponds to a calibration in which, additionally, $\beta=0$. For each activity we present the drop in each calibration relative to the baseline, as a percentage. Panel (a) presents results for the West; Panel (b), for the Brazil as a whole. 
Figure 10: Measuring the Contribution of Knowledge in the Steady State
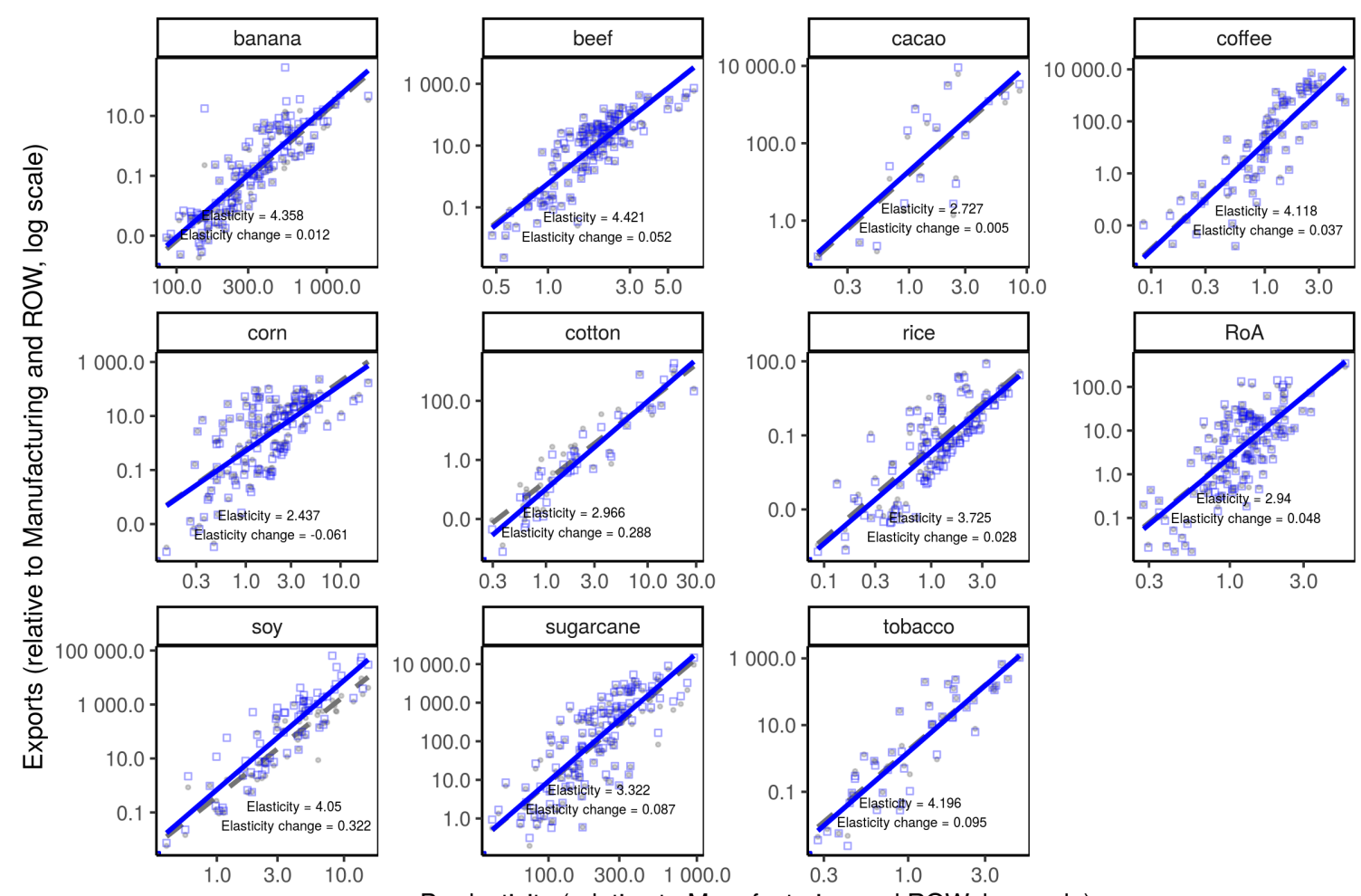

Productivity (relative to Manufacturing and ROW, log scale)

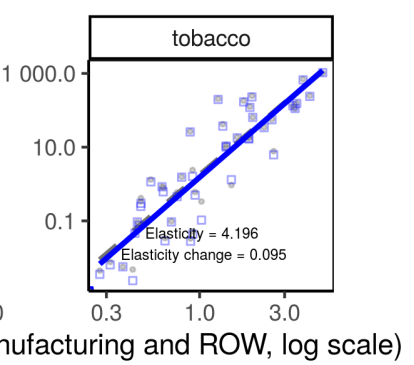

Parameterization: $\quad$ beta $=0 \quad \square \quad$ beta $=0.04$

Notes. Each panel corresponds to a crop and each observation is a region in Brazil. In each panel, the horizontal axis is the productivity of that crop (relative to manufacturing and relative to ROW, in logs) and the vertical axis shows exports in that crop (relative to manufacturing and relative to ROW,in logs). For each calibration we also report regression lines. 
Figure 11: Comparative Advantage, Migration, and the Losses from Autarky (2010)

(a) The Full Gains from Trade

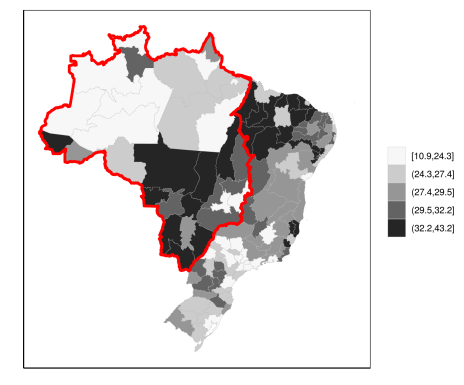

(c) Mapping the Contribution of Migration Opportunities

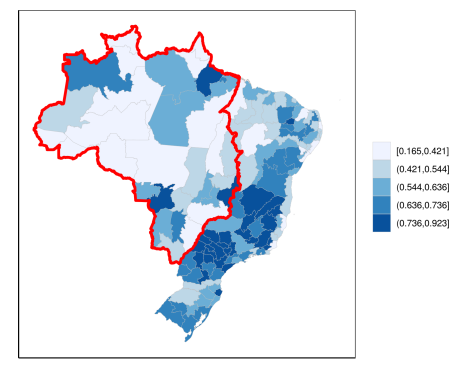

(e) Mapping the Contribution of Comparative Advantage

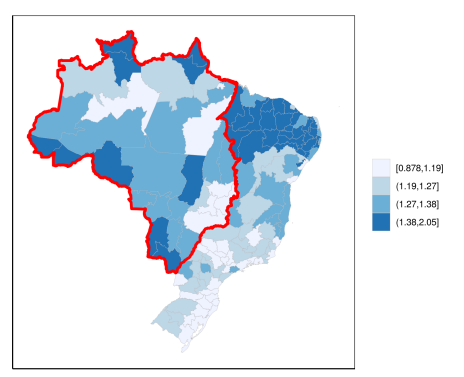

(b) The Contribution of Migration Opportunities

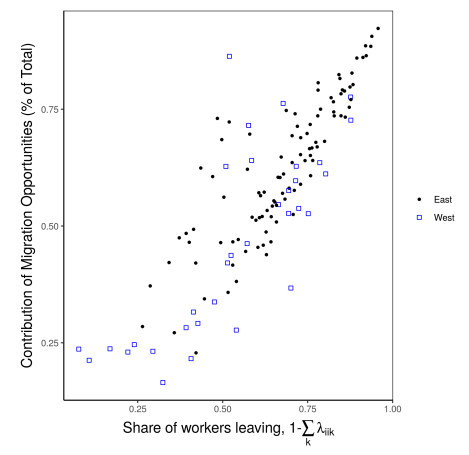

(d) Comparative Advantage and the GFT

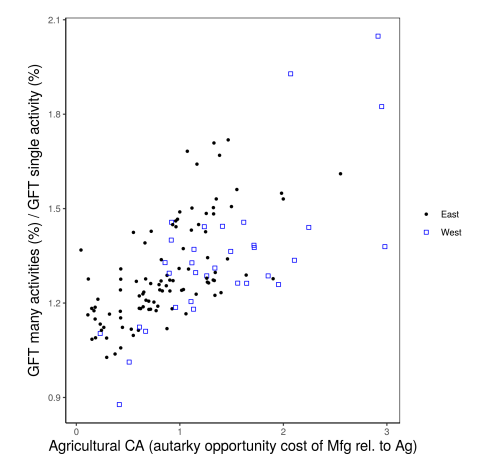

(f) The Interaction of Migration and Comparative Advantage

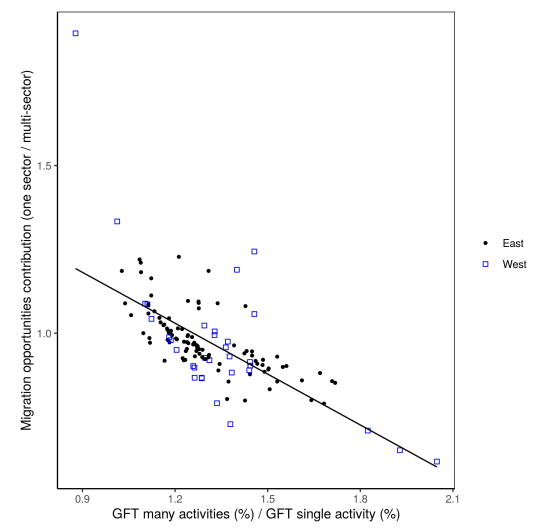

Notes: All simulations are for 2010 and each observation is a region. Panel (a) shows the welfare losses from letting each region go to full trade autarky, as a percent of baseline welfare. Panel (b): The horizontal axis the fraction of workers leaving that region in the baseline simulation. The vertical axis measures the ratio of the welfare cost that results solely from migration opportunities (i.e. setting the domestic contribution to zero) to the total costs and taking the ratio of $\hat{\Xi}_{i}$. Panel (c): shows the vertical axis of Panel (b). Panel (d): The vertical axis plots the ratio of the GFT with many activities to the GFT with one activity, both as percent of baseline. The horizontal axis shows the autarky opportunity cost of manufacturing relative to agriculture. Panel (e) shows the horizontal axis in Panel (d). Panel (f): The vertical axis is the same as in in Panel (d). The horizontal axis shows the change in the contribution of migration opportunities in going from a one-activity to a many-activity version of our model. 
Figure 12: The March to the West and the International Gains from Trade (2010)

(a) The Gains from International Trade

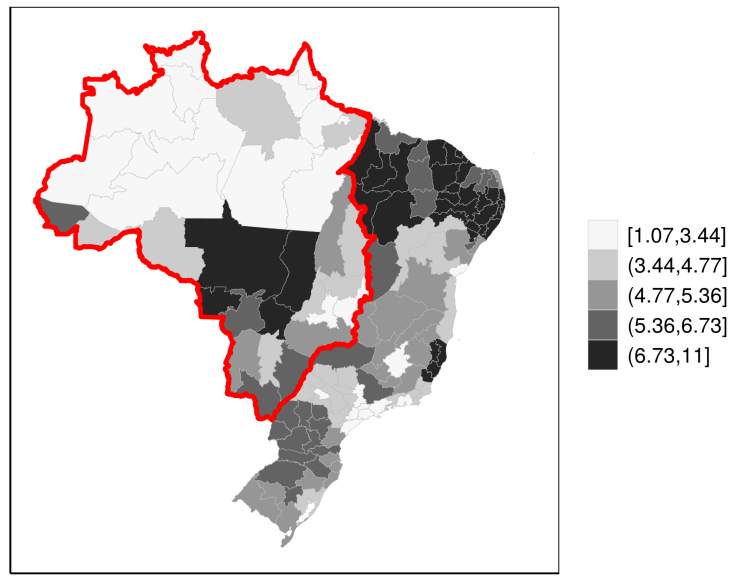

(b) Counterfactual Changes in International GFT

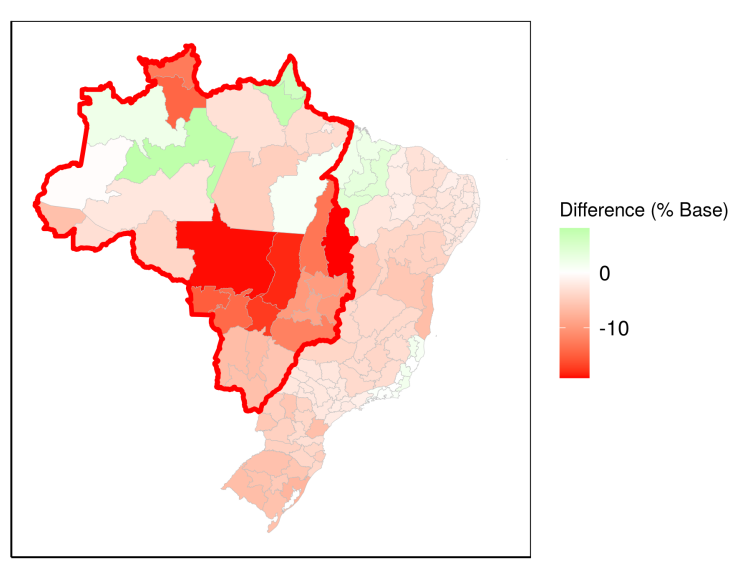

Notes: Panel (a) shows for each region the gains from trade with the rest world, defined as the welfare cost of prohibiting foreign trade only (but allowing domestic trade). Panel (b) subtracts the baseline gains from trade from the gains from trade in the counterfactual scenario (no East-West migration). 
Table 1: The Evolution of Brazil's Trade Specialization (1950-2010)

\begin{tabular}{|c|c|c|c|c|c|c|c|}
\hline & \multicolumn{3}{|c|}{ Brazil } & \multirow{3}{*}{$\begin{array}{r}\text { East } \\
2010 \\
(4)\end{array}$} & \multirow{3}{*}{$\begin{array}{r}\text { West } \\
2010 \\
(5)\end{array}$} & \multicolumn{2}{|c|}{ Exports $(\%)$} \\
\hline & 1950 & 1980 & 2010 & & & 1950 & 2010 \\
\hline & $(1)$ & $(2)$ & $(3)$ & & & $(6)$ & $(7)$ \\
\hline corn & 2.12 & 0.52 & 4.56 & 1.45 & 25.43 & 1.35 & 3.93 \\
\hline beef & 1.12 & 1.77 & 5.69 & 3.40 & 21.05 & 2.17 & 6.89 \\
\hline soy & 0.00 & 60.88 & 69.74 & 44.85 & 237.02 & 0.00 & 29.43 \\
\hline cotton & 9.41 & 0.72 & 3.28 & 2.16 & 10.83 & 6.23 & 1.79 \\
\hline restofag & 1.01 & 2.19 & 2.51 & 2.52 & 2.47 & 13.66 & 28.40 \\
\hline sugarcane & 18.82 & 27.91 & 52.28 & 57.32 & 18.36 & 5.70 & 16.13 \\
\hline rice & 0.19 & 0.07 & 0.43 & 0.48 & 0.06 & 0.44 & 0.56 \\
\hline coffee & 655.55 & 339.56 & 166.11 & 190.24 & 3.95 & 59.22 & 8.01 \\
\hline cocoa & 273.44 & 299.89 & 15.00 & 17.22 & 0.11 & 8.98 & 0.40 \\
\hline tobacco & 6.70 & 19.92 & 64.27 & 73.84 & 0.00 & 1.76 & 4.39 \\
\hline banana & 5.09 & 1.81 & 0.38 & 0.44 & 0.00 & 0.49 & 0.06 \\
\hline agriculture & 4.98 & 5.08 & 6.14 & 5.35 & 11.50 & 79.77 & 31.96 \\
\hline $\mathrm{mfg}$ & 1.00 & 1.00 & 1.00 & 1.00 & 1.00 & 20.23 & 68.04 \\
\hline
\end{tabular}

Notes: Columns (1) through (3) present our index of bilateral specialization for each activity (relative to manufacturing and relative to the rest of the world) for 1950, 1980, and 2010. Columns (4) and (5) present the same index broken down by East and West of Brazil, for 2010. Columns (6) and (7) present the share of each activity in Brazil's agricultural exports in 1950 and 2010. 
Table 2: The Relation between Farmers' Income, Choices, and Region of Origin

\begin{tabular}{|c|c|c|c|c|c|c|}
\hline & $\begin{array}{c}\text { OLS } \\
(1)\end{array}$ & $\begin{array}{c}\text { OLS } \\
(2)\end{array}$ & $\begin{array}{c}\text { OLS } \\
(3)\end{array}$ & $\frac{\text { PPML }}{(4)}$ & $\frac{\text { PPML }}{(5)}$ & $\begin{array}{c}\text { PPML } \\
(6)\end{array}$ \\
\hline \multicolumn{7}{|l|}{ a: Income (logs) } \\
\hline Farmers in origin & $\begin{array}{c}0.016^{* * *} \\
(0.005)\end{array}$ & $\begin{array}{c}0.023^{* *} \\
(0.010)\end{array}$ & $\begin{array}{c}0.047^{* * *} * \\
(0.016)\end{array}$ & $\begin{array}{c}0.045^{* * *} \\
(0.012)\end{array}$ & $\begin{array}{c}0.083^{* * *} \\
(0.020)\end{array}$ & $\begin{array}{l}- \\
-\end{array}$ \\
\hline $\mathrm{R}^{2}$ & 0.342 & 0.702 & 0.729 & - & - & - \\
\hline Obs & 6794 & 6794 & 5180 & 6794 & 5180 & \\
\hline \multicolumn{7}{|c|}{ b. Farmers in destination (logs) } \\
\hline Farmers in origin & $\begin{array}{c}0.074^{* * *} \\
(0.007)\end{array}$ & $\begin{array}{c}0.075^{* * *} \\
(0.014)\end{array}$ & $\begin{array}{c}0.101^{* * *} \\
(0.022)\end{array}$ & $\begin{array}{c}0.120^{* * *} \\
(0.013)\end{array}$ & $\begin{array}{c}0.131^{* * *} \\
(0.023)\end{array}$ & $\begin{array}{c}0.165^{* * *} \\
(0.011)\end{array}$ \\
\hline $\mathrm{R}^{2}$ & 0.183 & 0.751 & 0.774 & - & - & - \\
\hline Obs & 7375 & 7375 & 5609 & 7375 & 5609 & 127950 \\
\hline \multicolumn{7}{|c|}{ c. Worker heterogeneity parameters } \\
\hline$\kappa$ & 4.625 & 3.260 & 2.148 & 2.666 & 1.578 & \\
\hline$\beta$ & 0.016 & 0.023 & 0.047 & 0.045 & 0.083 & \\
\hline Dest-Act-Year FE & $\mathrm{Y}$ & $\mathrm{Y}$ & $\mathrm{Y}$ & $\mathrm{Y}$ & $\mathrm{Y}$ & $\mathrm{Y}$ \\
\hline Dest-Orig-Year FE & & $\mathrm{Y}$ & $\mathrm{Y}$ & $\mathrm{Y}$ & $\mathrm{Y}$ & $\mathrm{Y}$ \\
\hline Above Q1 & & & $\mathrm{Y}$ & & $\mathrm{Y}$ & \\
\hline Include zeros & & & & & & $\mathrm{Y}$ \\
\hline
\end{tabular}

Notes: ${ }^{*} /{ }^{* *} /{ }^{* * *}$ denotes significance at the 10/5/1 percent level. Standard errors clustered at the destination-crop-year level in parenthesis. The unit of observation is a destination-activity-origin-year cell. Column 3 and 5 drop the sample in the bottom quartile in the distribution of the dependent variable. "Farmers in origin" is the log of farmers in the same activity in the region of origin lagged by thirty years. Column 6 includes zeros in all bilateral migration pairs for destination regions with at least one producing farmer. Our sample excludes return migrants and non-migrants. 


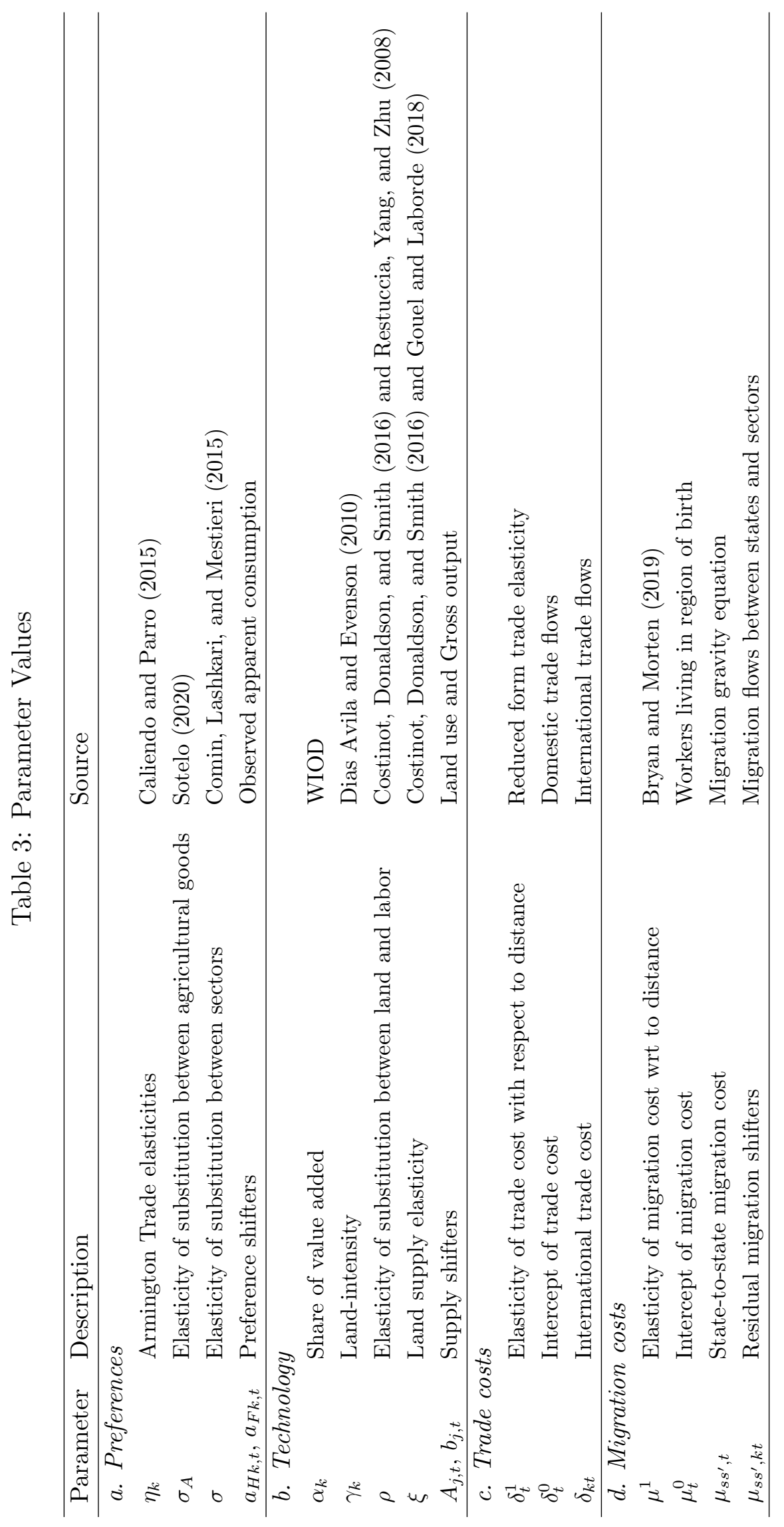


Table 4: Description of the Parameters Recovered in the Calibration

\begin{tabular}{lrrr}
\hline & \multicolumn{3}{r}{ Year } \\
\cline { 2 - 4 } & 1950 & 1980 & 2010 \\
& $(1)$ & $(2)$ & $(3)$ \\
\hline a. Migration costs & 33.62 & 20.49 & 18.38 \\
Average migration costs & 2.21 & 1.91 & 1.78 \\
Migration costs within states & 103.04 & 42.61 & 37.84 \\
Migration costs between states: East versus West & 60.85 & 24.36 & 21.45 \\
Migration costs between states: within the West & 58.04 & 29.41 & 26.19 \\
Migration costs between states: within the East & 1.00 & 0.80 & 0.72 \\
Elast. of migration costs w.r.t. travel distance & & & \\
b. Productivity & 0.48 & 0.75 & 0.82 \\
Productivity in manufacturing in the West relative to the East & 0.95 & 1.25 & 1.56 \\
Productivity in agriculture in the West relative to the East & 0.40 & 1.86 & 1.67 \\
- Soybeans & 1.34 & 0.87 & 0.80 \\
- Livestock & 1.01 & 0.97 & 2.04 \\
- Corn & 0.31 & 0.52 & 1.31 \\
Productivity of land supply in the West relative to the East & & & \\
\hline c. Trade costs & 8.83 & 5.13 & 3.96 \\
Trade cost between Brazil and RoW - manufacturing & 9.70 & 5.42 & 4.06 \\
Trade cost between Brazil and RoW - agriculture & 0.15 & 0.14 & 0.12 \\
Elast. of trade cost w.r.t. travel distance &
\end{tabular}

Notes: This table shows results from the calibration of the model. Migration costs are presented in terms of its harmonic average. Productivity is averaged using employment weights. International trade costs are averaged using trade-flow weights. The elasticity of migration cost with respect to travel distance is the slope of a regression of the log of estimated migration costs between states against the log of travel distance. 